HARDY JOSÉ SANTOS DE MIRANDA

\title{
RECONSTRUÇÃO TRIDIMENSIONAL PARA OBJETOS DE HERANÇA VIRTUAL
}


HARDY JOSÉ SANTOS DE MIRANDA

\section{RECONSTRUÇÃO TRIDIMENSIONAL PARA OBJETOS DE HERANÇA VIRTUAL}

Dissertação de Mestrado apresentada à Escola Politécnica da Universidade de São Paulo no Programa de Pós-Graduação em Engenharia Elétrica para obtenção do Título de Mestre em Ciências

Orientador: Prof. Dr. Ricardo Nakamura 
HARDY JOSÉ SANTOS DE MIRANDA

\section{RECONSTRUÇÃO TRIDIMENSIONAL PARA OBJETOS DE HERANÇA VIRTUAL}

Dissertação de Mestrado apresentada à Escola Politécnica da Universidade de São Paulo no Programa de Pós-Graduação em Engenharia Elétrica para obtenção do Título de Mestre em Ciências

Área de Concentração:

Engenharia de Computação e Sistemas Digitais

Orientador: Prof. Dr. Ricardo Nakamura 
Catalogação-na-publicação

Miranda, Hardy José Santos de

Reconstrução Tridimensional Para Objetos de Herança Virtual / H. J. S.

Miranda -- São Paulo, 2018.

$72 \mathrm{p}$.

Dissertação (Mestrado) - Escola Politécnica da Universidade de São

Paulo. Departamento de Engenharia de Computação e Sistemas Digitais.

1.RECONSTRUÇÃO (GEOMETRIA E MODELAGEM COMPUTACIONAL) 2.COMPUTAÇÃO GRÁFICA 3.FOTOGRAMETRIA I.Universidade de São Paulo. Escola Politécnica. Departamento de Engenharia de Computação e Sistemas Digitais II.t. 


\section{AGRADECIMENTOS}

A todos os amigos que durante nossa caminhada permitiram que evoluíssemos juntos, em especial aos amigos do Interlab e do PCS (Cleber, Makoto, Elen, Lucy, Wiliam, Roberto) que contribuíram para uma experiência fantástica durante esse tempo de pesquisa e ativamente me ajudaram a crescer.

Em especial ao Prof. Dr. Ricardo Nakamura pela serenidade, paciência, incentivo e amizade, seu apoio e visão foram primordiais para este trabalho.

À Mariza Leone, que seja sempre essa pessoa doçe, a sua amizade é muito valiosa.

À Yasmine Lima, seu apoio e companheirismo me ajuda a ser sempre uma pessoa melhor.

À Selma e Izabelle pelas conversas, ajudas, ideias e estarem sempre presente.

À toda a minha família, que sempre acreditou em mim e permitiu que eu chegasse conde cheguei.

Aos meus pais, que sem seu apoio e compreensão isso não seria possível. 
"It's just a flesh wound"

(The Black Knight) 


\section{RESUMO}

Em um primeiro momento as novas tecnologias podem impulsionar acentuadamente a interação com um elemento, o que pode levar à um aprendizado significativo, mas esse impulso reduz assim que a interação se torna comum ou até mesmo repetitiva. Quando essa nova tecnologia se torna natural para o usuário ela deixa de ser uma novidade e se torna uma ferramenta. O uso de Imagens Geradas por Computador (IGC) experienciaram exatamente isso, décadas atrás, mas estão constantemente sendo iteradas de acordo com suas necessidades de reavaliação frequentes. Com o desenvolvimento das IGC as imagens tridimensionais deixaram de ser um formato excessivamente complicado, ao passo que hardwares e conceitos foram adentrando objetos do dia-a-dia como smartphones, webcams, câmeras, aplicativos de geração de malhas 3D, etc. O seu uso com objetivos museológicos se tornou evidente no campo da herança cultural para arquivamento e comunicação. Sendo assim, para verificar a viabilidade para uma solução fácil e de baixo custo visando novos usuários, diferentes tipos de métodos não-destrutivos de reconstrução baseadas na superfície foram analisados. Para isso, identificou-se a qualidade do resultado de precisão da malha, a rastreabilidade e a compatibilidade dos mesmos. Com esse objetivo, foi proposto um método com um conjunto de métricas que podem ser aplicadas para determinar a usabilidade de um objeto reconstruído com um fim específico. Quatro artefatos arqueológicos foram escaneados usando métodos de vídeo fotogrametria e vídeo de profundidade, a serem comparados com substitutos escaneados a laser.

Depois de analisar os escaneamentos dos mesmos objetos com esses diferentes métodos, concluiu-se que a fotogrametria é capaz de gerar com rapidez um modelo altamente detalhado, mas com várias distorções. A profundidade de câmera gerou superfícies mais suaves e maior incidência de erros. Em última análise, cada método apresentado demonstra múltiplas possibilidades para materialização, dependendo do objetivo, resolução e de quão detalhado o objeto deve ser para ser corretamente compreendido.

Palavras-chave: Reconstrução 3D, Imagens Geradas por Computador, Fotogrametria, Mapa de Profundidade, Herança Virtual, Arqueologia Virtual. 


\begin{abstract}
At first glance new technologies can provide an engaging way to interact with a subject which may induce a meaningful learning, but it soon falls short when it becomes common or even repetitive. As this new technology becomes natural to the user, it no longer relies on novelty and goes into another condition, as a tool. The use of Computer-Generated Imagery (CGI) experienced exactly this, decades ago, but as it's constantly being iterated upon it needs to be reassessed often. As CGI goes, the tridimensional imagery as an overcomplicated format started to fade, as new hardware and concepts made way into everyday objects such as smartphones, webcams, cameras, 3D mesh generation apps, etc. It's use for museological purposes became clear in the field of cultural heritage for archiving and communication. So, to verify the viability for a low-cost and easy to use solution aiming to novice users, different types of non-destructive methods surface based reconstructions are analyzed to identify the quality of the resulted mesh based on precision, traceability and compatibility. To this end, it was proposed a method with a set of metrics which can be used to point out the usability of a reconstructed object for a specific end. Four archaeological artifacts were scanned using the video photogrammetry method and the depth video method, to be compared with a laser scanned surrogate.

After analyzing the scans of the same objects with these different methods, the conclusion is that photogrammetry has the power to provide a highly detailed model very fast but with several distortions. The depth camera provided smoother surfaces and higher error. Ultimately, each method presented multiple possibilities for materialize itself, depending on target resolution and how detailed the object must be to correctly understand it.
\end{abstract}

Keywords: 3D Reconstruction, Computer-Generated Imagery, Photogrammetry, Depth map, Virtual Heritage, Virtual Archaeology. 


\section{LISTA DE FIGURAS}

Figura 1: Croqui para cortes transversais em um fóssil. .....................................18

Figura 2: Geração de tomografias computadorizadas por Raio-X...........................20

Figura 3: Tomografia de uma múmia egípcia que viveu entre 945 A.E.C. e 715 A.E.C. $\mathrm{Na}$ imagem é demonstrado o contraste entre o material do sarcófago, o ar, o linho e o espécime, bem como o ajuste de alcance dos pixels mostrados de uma imagem para outra. 21

Figura 4: Braço mecânico e posicionamento do fóssil. .24

Figura 5: Fluxo de geração de modelos a partir de dados de superfície 29

Figura 6: Etapas de metodologia 39

Figura 7: Ponta de flecha (ver anexos) 40

Figura 8: Borda de vaso (ver anexos) 41

Figura 9: Machadinha (ver anexos)

Figura 10: Vaso (ver anexos)

Figura 11: Reconstrução pelo 123D Catch

Figura 12: Scaner à laser utilizado 46

Figura 13: Setup com tripé, $h_{1}=70 \mathrm{~cm}, h_{2}=28 \mathrm{~cm}, d=60 \mathrm{~cm}$

Figura 14: Vaso, área interna .49

Figura 15: Sistema do modelo SR300 .50

Figura 16: Reconstrução de vários cubos empilhados .52

Figura 17: Modelos capturados em movimento .52

Figura 18: Modelos reconstruídos em tempo real .54

Figura 19: Registro Geral (esquerda) e o Registro Fino (direita. .56

Figura 20: Código de cor para cada cluster...... 57

Figura 21: Mapa de desvio dos objetos capturados com a câmera 59

Figura 22: Mapa de desvio dos objetos capturados com a RealSense SR300 62 


\section{LISTA DE TABELAS}

Tabela 1: Critérios para a escolha do sistema de digitalização adequado. .28

Tabela 2: Vantagens e desvantagens de cada formato de arquivo 3D. Estão grifados os defeitos mais críticos. .35

Tabela 3: Aspectos essenciais para peças digitalizadas. .42

Tabela 4: Número de quadros por coleção .49

Tabela 5: Tempo de captura para cada peça .53

Tabela 6: Relação de pontos nos artefatos resultados de fotogrametria .57

Tabela 7: Mapeamento dos clusters no método fotogramétrico .58

Tabela 8: Relação de pontos nos artefatos resultados pela SR300 60

Tabela 9: Mapeamento dos clusters nos resultados pela SR300. 60

Tabela 10: Relação os dois métodos .63 


\section{SUMÁRIO}

1 INTRODUÇÃO

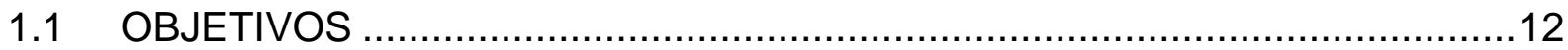

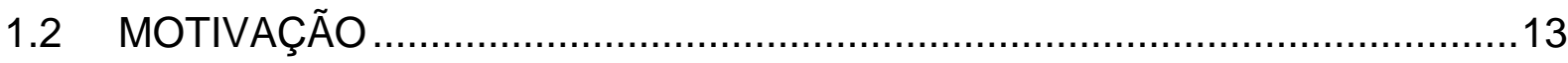

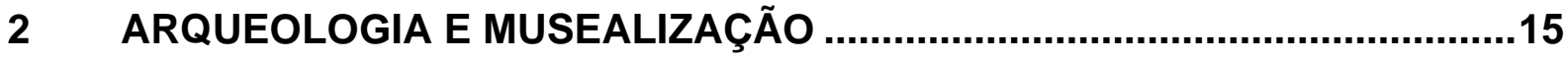

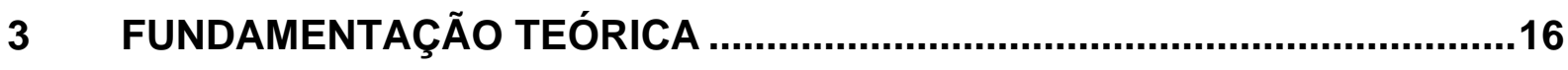

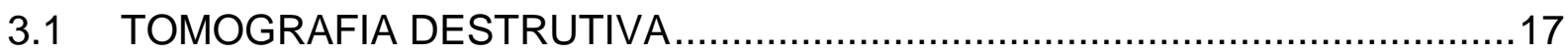

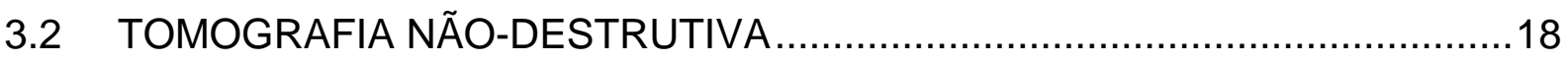

3.2.1 Tomografia Computadorizada (Raios-X e Neutrons) ….............................19

3.2.2 Tomografia Ótica e Ressonância Magnética............................................22

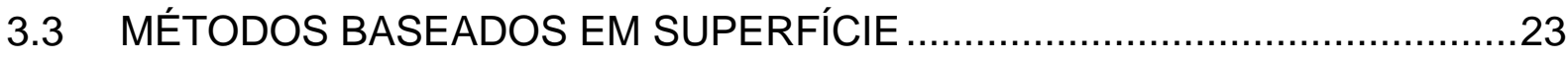

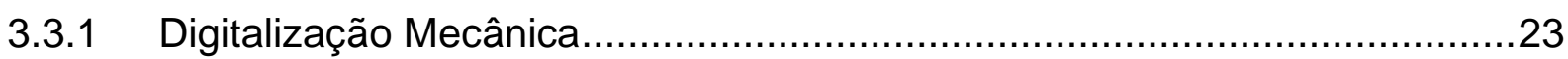

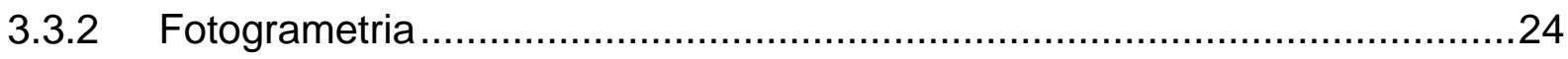

3.3.3 Distância Por Alcance Ótico .......................................................................26

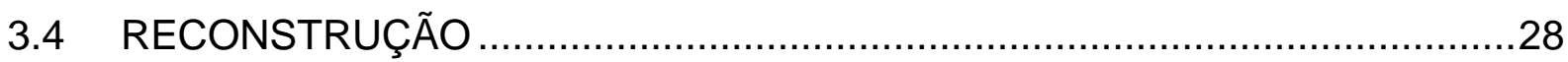

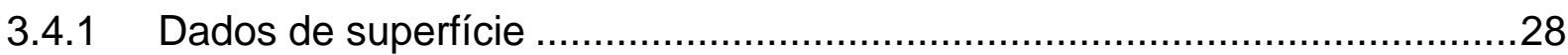

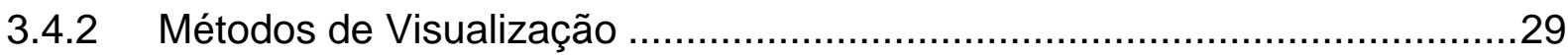

3.5 TÓPICOS SOBRE MUSEOLOGIA E ARQUEOLOGIA …...............................30

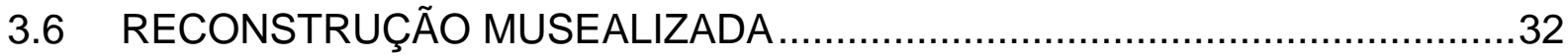

3.6.1 Métricas de Qualidades e suas aplicações ...............................................33

4 APLICAÇÕES EM TRABALHOS CORRELATOS …....................................38

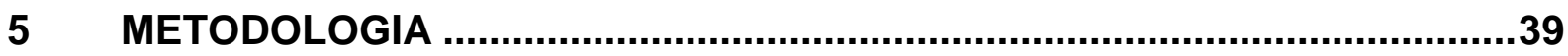

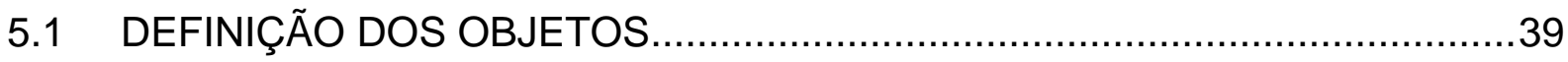

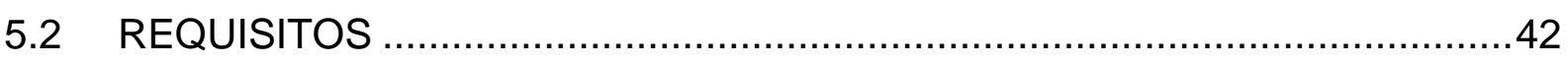

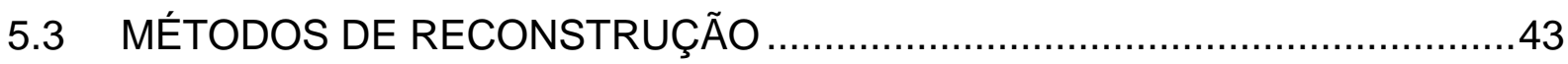

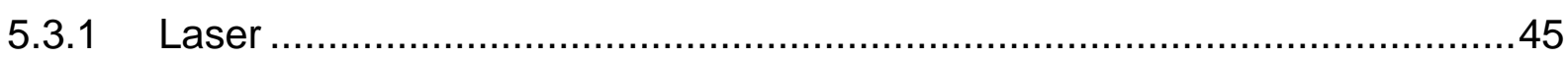




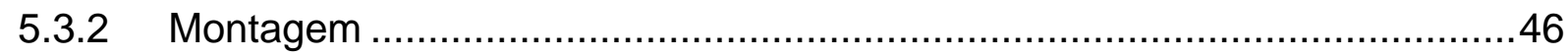

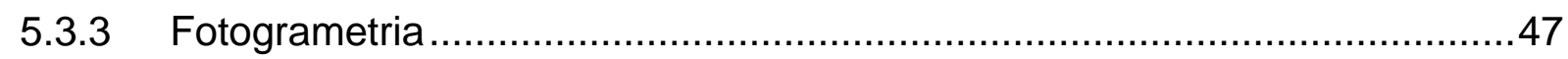

5.3.4 Profundidade e luz estruturada ..................................................... 50

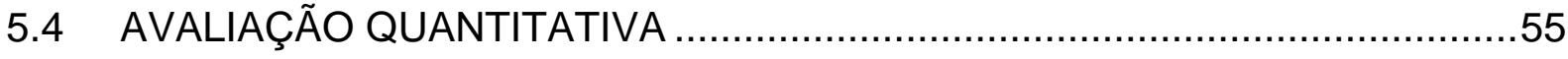

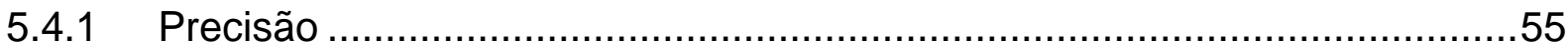

5.4.2 Rastreabilidade e Compatibilidade .................................................63

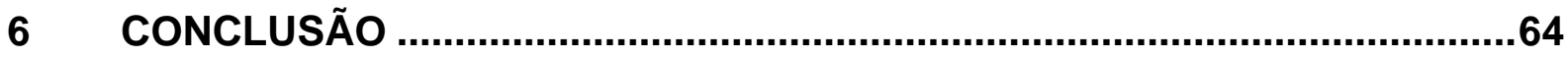

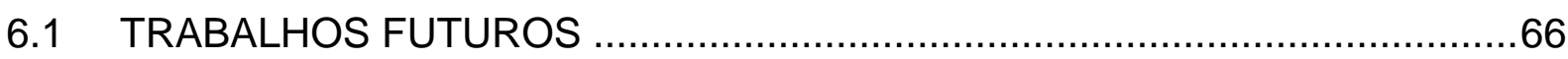

REFERÊNCIAS.........................................................................................67

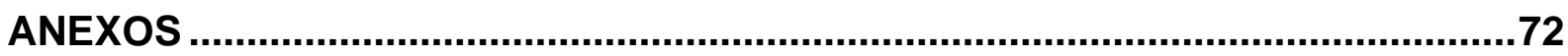




\section{INTRODUÇÃO}

É crescente a utilização de realidade virtual [LAHA, BOWMAN e SOCHA, 2014] como ferramenta em processos museais e educacionais. A arqueologia e a paleontologia têm a possibilidade de usá-la para salvaguarda ou recriação de artefatos, seja para propósitos culturais, artísticos, religiosos ou históricos. Esta aplicação é denominada como Herança Virtual, ou Virtual Heritage, e se trata de uma extensão digital da Herança Cultural ao agregar uma grande flexibilidade ao modelo de apresentação de conteúdo por fornecer maior imersão ao material científico, algo essencial para incentivar experiências educativas.

A combinação entre educação e arqueologia, paleontologia ou etnologia pode oferecer uma visão diferenciada na abordagem do conceito de herança virtual, e um leque de novas possibilidades pode ser encontrado. Isso acontece através da musealização de cada uma dessas áreas, e pode impactar profundamente o campo da comunicação museal ao permear diretrizes preservacionistas e o tratamento curatorial. Entretanto, muitos desafios emergem a partir da incorporação de novos processos e planejamentos museológicos, e em como a valorização da herança ou patrimônio é inserida na educação [BRUNO, 2014].

A criação de modelos tridimensionais dos artefatos com metadados oferece a demonstração de propriedades outrora difíceis de serem percebidas apenas com o suporte imagético. Logo, ao expandir o nível de interação desde a imersão em um ambiente virtual até o objeto físico e possibilitar a extração de artefatos de prisões geomorfológicas [CUNNINNGHAN et al, 2014], fica claro que formatos eletrônicos podem fornecer apoio à preservação do patrimônio e herança cultural.

\subsection{OBJETIVOS}

Os museus são essencialmente instituições de herança cultural, e têm encontrado nas mídias digitais novas possibilidades para a transcender a barreira entre seus artefatos e o público, de maneira imersiva. Para isso, pode ser proposto um modelo de musealização para peças virtuais tridimensionais ideal para salvaguarda em massa, que consiste na:

Obtenção de dados de superfícies; 
Aplicação de métodos para reconstrução;

Avaliação quantitativa dos modelos;

Verificação da métrica de qualidade.

Dessa forma, o principal objetivo deste trabalho consiste na proposta de método para digitalização de patrimônios culturais (objetos), incluindo-se a técnica computacional e o dispositivo de aquisição, com enfoque em peças arqueológicas do Brasil. Para tanto, será realizada a avaliação de técnicas existentes e aplicadas nesse domínio em conjunto com dispositivos disponíveis tais como Microsoft Kinect e Intel RealSense, considerando-se aspectos de qualidade pautados na área da herança cultural.

\subsection{MOTIVAÇÃO}

A arqueologia é o estudo das atividades humanas (formas econômicas e políticas), a partir de evidências, para suprir lacunas no conhecimento histórico. Preocupa-se principalmente com processos sociais e culturais da antiguidade, e divide-se em várias subáreas como: arqueologia histórica, etnográfica e arqueometria. O termo arqueologia histórica foi cunhado por historiadores no "mundo novo", para delimitar os estudos que compreendem sociedades com registros escrito [FUNARI, 2007] (dela são excluídos os estudos sobre cidades europeias, pois costuma ter nomes específicos, como arqueologia grega, etc.). A arqueologia etnográfica estuda grupos ainda existente de pessoas, para a compreensão do passado. Por fim, a arqueometria busca sistematizar matematicamente medidas arqueológicas. A arqueologia pode estar interligada a outros campos do conhecimento humano para expandir a compreensão histórica de forma multidisciplinar, como a arqueoantropologia, arqueopaleontologia, etc.

A paleontologia estuda os restos mineralizados de seres vivos que já existiram, provendo sua linha do tempo tratando os modos de vida, condições ambientais e bióticas, as causas de morte, extinção e as relações evolutivas entre eles. Contribuindo assim para o entendimento sobre a origem e evolução da vida na terra [CASSAB, 2004].

O ensino preliminar da arqueologia e da paleontologia são fundamentais para formação de cidadãos cientes da realidade a qual estão inseridos, e estão incluídos 
como recomendação estabelecida nos Parâmetros Curriculares Nacionais (PCN) como tema dos programas de História do ensino fundamental e médio para a primeira, nos programas de Biologia e Geologia (na disciplina Biologia) para a segunda, entretanto a suas abordagens são constantemente subutilizadas ou sequer realizadas devido à dependência no material didático utilizado e sua defasagem [ANTUNES, 2013], esta realidade é resultado de uma sequência de fatores determinantes. Um obstáculo que gera entraves na divulgação desta área, é a falta de tempo dentro da sala de aula para a transmissão do conhecimento, o que gera a necessidade do incentivo na busca por conta própria dos estudantes por entre explorações multimidiáticas, algo dificultado pela falta de estabelecimento de uma relação entre a experiência dos estudantes e o conteúdo.

Um jogo, seja digital ou não, além de lúdico oferece um sistema de regras fundamentais para o estímulo físico e mental, tornando uma ferramenta didática indispensável para o processo de ensino-aprendizagem [NEVES et al, 2008, pg 108]. Na mesma linha, um ambiente virtual como ferramenta de ensino também é reflexo da escassa tradução das pesquisas científicas para o público, e associado às poucas alternativas ao ensino de paleontologia fora da sala de aula, o desenvolvimento de um plano para a compreensão visual e ativa de artefatos e sítios que considerados patrimônio cultural deve ser prioridade, como mostra o trabalho realizado em Sergipe por Sobral e Siqueira (2007), usando jogo de tabuleiro para ensinar paleontologia. Idealizando promover a análise de espécies por estudantes e a construção de uma documentação para a confecção de um jogo direcionado ao ensino da paleontologia, uma única espécie deve ser usada para fim de obter o maior nível científico e artístico possível. 


\section{ARQUEOLOGIA E MUSEALIZAÇÃO}

A arqueologia pode estar muitas vezes vinculada a empreendimentos que trazem impacto negativo às sociedades envolvidas, e está completamente dependente do contexto político em todas as esferas. Visto que todas as pesquisas arqueológicas (ou Patrimônio Arqueológico) são configurados como bens da União, e por isso são restringidas apenas a especialistas [BRUNO, 2013]. Então, órgãos como o Instituto Brasileiro de Museus (IBRAM) e o Instituto de Patrimônio Histórico Nacional (IPHAN) estão inseridos como as ferramentas federais, e funcionam como avaliadores do impacto arqueológico de obras de médio e grande porte, bem como a salvaguarda do patrimônio cultural.

No âmbito museal, o colecionismo "foi a primeira expressão de uma hierarquia política, econômica e social" [CARLAN, 2008]. Desde o século VIII é possível reconhecer iniciativas de preservação, recolhimento e recuperação, onde neste caso tratava-se de leis estabelecidas por Carlos Magno, para fins de lembrança da cultura romana. No caso do Brasil, foi criado em 1818 o Museu Real (Museu Nacional) por Dom João VI com uma coleção de História Natural doada pelo mesmo.

Hoje, muito além do caráter colecionista do qual nasceu, o museu busca atuar na investigação (pesquisa), na preservação e na comunicação. Apesar da pesquisa fazer parte do segundo plano no Brasil, ela enriquece a compreensão do artefato fazendo relações entre o homem, o objeto, o espaço e o patrimônio cultural. Demonstrando assim, que o patrimônio se trata de todo ou qualquer artefato com conhecida importância cultural, se mostra um termo intimamente relacionado com a apropriação do objeto / local a um povo [BRUNO, 2014].

A partir do momento que a investigação é realizada e o posicionamento cultural do patrimônio passa pelo processo compreensão, significa que está interpolando pelos processos da musealização, e assim adquirindo significados novos como objetos semióforos [BRUNO, 2014], logo, gerador de uma nova realidade a partir do momento de sua compreensão. É o que consiste uma herança, o patrimônio musealizado.

\footnotetext{
"As instituições museológicas são antropofágicas, ressignificam fragmentos do patrimônio para parcelas da sociedade. Analisar a inserção do patrimônio arqueológico nos museus é um exercício complexo, dado que uma peculiaridade caracteriza a interface entre Arqueologia e Museologia: a antropofagia museológica se desenvolve sobre uma antropofagia arqueológica.
} 
No contexto museológico, os processos de salvaguarda e comunicação desses vestígios, agora semióforos (POMIAN, 1984) ${ }^{1}$, também são antropofágicos, operam recortes e tem o poder de ressignificar essas evidências.

O conceito de antropofagia, proposto por Chagas (2005) $)^{2}$, caracteriza o processo seletivo e devorador dos museus, seu poder em incorporar aspectos materiais e imateriais das sociedades, ressignificando-os. Denomino de antropofagia arqueológica a apropriação e ressignificação feita pela Arqueologia, que seleciona aspectos da materialidade das sociedades, alçando-os a patrimônio. Por sua vez, a antropofagia museológica se dá nos processos de musealização desse patrimônio, onde novas apropriações, recortes e metamorfoses de sentido são efetivados". [BRUNO, 2013, p.17]

Quando pensamos no termo antropofagia, encontramos uma aproximação (resposta parcial) ao problema desde trabalho, esse termo carrega uma violência intrínseca no sentido de uma cultura que devora outra [BRUNO, 2014]. Isso reflete nos caminhos da pesquisa museal.

Segundo Bruno (2013), "o cenário atual da Arqueologia Brasileira tem evidenciado desafios específicos no que concerne ao uso plural desses recursos, desafios que requerem um olhar interdisciplinar", em vista disso, o uso de visualização de dados tridimensionais na paleontologia, arqueologia e etnografia, pode agregar as vantagens da virtualidade, limitadas apenas à necessidade requerida e pela captação dos objetos em 3D. Ela pode oferecer o seccionamento, isolamento, reconstrução [ANDREADIS et al, 2015] e manipulação [MITSOPOULOU et al, 2015], além de eliminar a possibilidade de danos [HUGHES, 2011]. No entanto, ela é percebida como dificultosa à primeira vista, apesar de haver extensa expressão de detalhes técnicos expostos sobre cada técnica disponível. Essa percepção se dá principalmente pela escassez de comparações mais profundas entre essas técnicas.

\section{FUNDAMENTAÇÃO TEÓRICA}

Segundo Sutton et al (2014), o estudo de fósseis tridimensionais através de visualizações digitais (ou fósseis virtuais), é definido como paleontologia virtual. Foi no início da década de 1980 que fósseis começaram a ser virtualizados para

1 POMIAN, K. 1984. Coleção. IN: Enciclopédia Einaudi. v. I Memória - História. Lisboa: Imprensa Nacional-Casa da Moeda. 1ํe., pp. 51-86.

${ }^{2}$ CHAGAS, M. 2005. Museus: antropofagia da memória e do patrimônio. Revista do Patrimônio Histórico e Artístico Nacional, n.31, pp.15-25. 
documentação e reconstrução tridimensional, com 0 advento da tomografia computadorizada de raios- $X$. Apesar de ser antigo o emprego de várias técnicas paleontológicas para dados bidimensionais, é constante a necessidade do uso de material preservado tridimensionalmente para fins de estudo.

O mesmo conceito de paleontologia virtual pode ser aplicado a outros campos das humanidades, onde a visualização digital pode fazer novas conexões entre a sociedade e a pesquisa. Dos quais se destacam a arqueologia e a etnografia, em que ambas incorporam uma vertente preservacionista contrastada com a necessidade de se fazer os artefatos acessíveis ao maior público possível [WEBER, 2014]. Apesar disso, práticas arqueológicas sempre possuíram a inevitabilidade da manipulação física, como em uma escavação, e logo incorpora traços destrutivos, mas a digitalização tridimensional tem a potência de causar mudanças profundas nesse paradigma [ROOSEVELT et al, 2015]. A seguir alguns métodos de coleta de dados serão apresentados.

\subsection{TOMOGRAFIA DESTRUTIVA}

Apesar da tecnologia de visualização digital ser de importância reconhecida [LAYCOCK, 2015], é uma ideia que encontra seu início desde a entrada do século XX. Nesse momento foi implementada a adaptação do seccionamento seriado usado em biologia, para artefatos paleontológicos por um pesquisador de Oxford chamado William Sollas. No caso do método de Sollas, o material era serrado tomograficamente em intervalos de $25 \mu \mathrm{m}$, cada superfície era fotografada e o traçado manual era realizado em placas fotográficas de vidro. Sollas também previu a criação de um modelo físico, usando cada tomografia como base para um modelo em cera ou papelão que poderia ser utilizado para a geração de um objeto inteiro.

Esse método, caracteriza-se como um tipo de tomografia destrutiva. Nela, cada fatia sequencial, obtida pelo corte transversal físico do objeto (Figura 1) é resguardada em formato fotográfico, mecânico (desenho, frottage e afins) ou por modelo (escultura), para posterior análise ou reconstrução tridimensional [RYKACZEWSKI, 2015]. Embora precursor do campo, causa danos irreparáveis ao objeto e seu uso deve ser minuciosamente estudado além de bastante demorada, porém provê reconstruções de alta fidelidade. 
Figura 1: Croqui para cortes transversais em um fóssil.

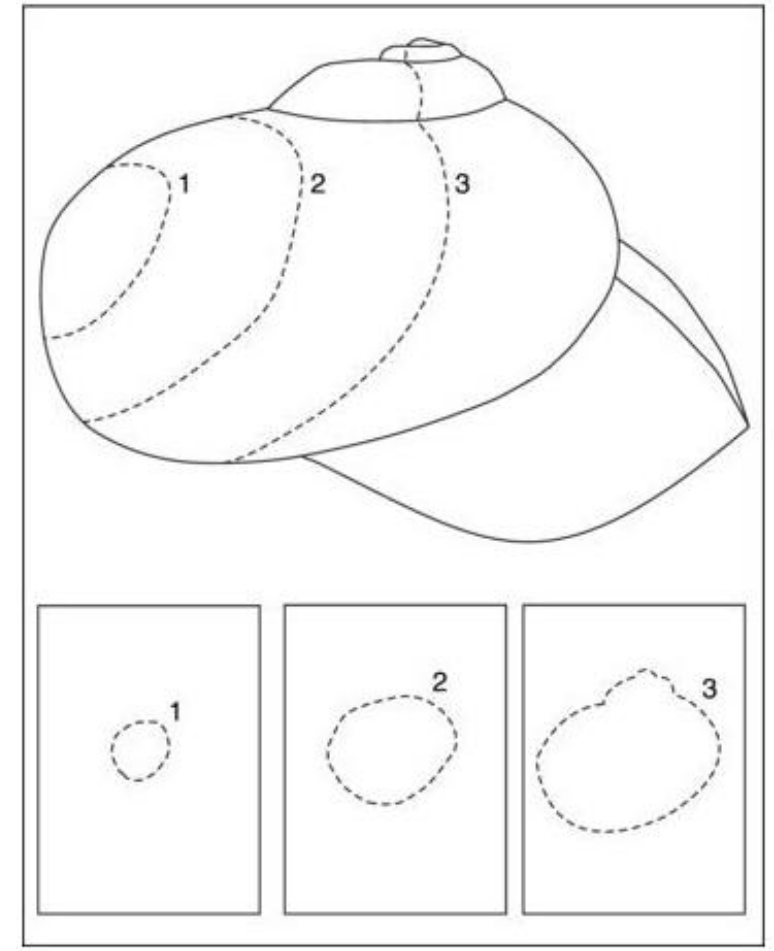

Fonte: SUTTON, RAHMAN e GARWOOD, 2014, Capítulo 1, Figura 1.2.

A tomografia destrutiva conta com métodos que envolvem a exposição das superfícies do objeto, eles são: O método Ótico-Físico e o de Feixes Concentrados de Íon (Focused Ion Beans - FIB). Entre eles a maior diferença é que o primeiro consiste na serragem, laminação ou moagem em objeto grandes, enquanto que por outro lado o segundo utiliza de microscópio de feixes de íon de gálio menores que $1 \mu \mathrm{m}$, para laminar de forma precisa objetos muito pequenos. O FIB usa geração de imagens por elétrons.

\subsection{TOMOGRAFIA NÃO-DESTRUTIVA}

Partindo do ponto de que a preservação do objeto como patrimônio é tão essencial quanto seu estudo, com os incessantemente evolutivos novos processos museais, métodos inovadores precisaram ser concebidos de forma que o patrimônio permaneça livre de danos. Assim, com o advento da tomografia computadorizada de Raios-X (X-Ray Axial Computed Tomography - CT ou CAT) na década de 1970, uma verdadeira revolução teve início [SUTTON, 2014]. Desde então sua popularidade aumentou, bem como a sua disponibilidade. 
Os fósseis são sutis ao escaneamento por tomografia de raios- $\mathrm{X}$, por resultar em alto contraste entre ele e o material rochoso predominante em sua estrutura (Matriz), em razão disso deduziu-se que o escaneamento CAT ofereceria um grande potencial para a paleontologia, o que foi demonstrado apenas anos depois por Tate e Cann (1982). Por outro lado, no contexto arqueológico, esse método de escaneamento é notadamente superior à análise manual, como evidenciado em 1977 por Derek Harwood-Nash ao aplicá-lo sobre o cérebro ressecado e em uma múmia, na qual não se fez necessária uma autópsia, onde acontece a destruição da múmia com a retirada das bandagens e sua quebra sistemática. Por essa razão, em muitas múmias esse processo é rejeitado, pois normalmente as encontradas com maior qualidade [HUGHES, 2011] passam a ser consideradas patrimônios e quererem iniciativas preservacionistas como caráter principal em seu manuseio.

"Quando se fala em criar imagens de artefatos arqueológicos, não há
competição para a tomografia computadorizada, pois existem grandes
dificuldades que previnem outras modalidades de geração de imagens 3D
em arqueologia. Por exemplo, geração de imagens por ultrasom depende
da propagação de ondas de alta frequência através de um material de
densidade uniforme. Como as múmias contém muito ar entre as
bandagens, o ultrasom será altamente refletido nas interações entre o
linho e o ar [...]. A imagem por ressonância magnética é geralmente
imprópria para uso em arqueologia pois depende do material possuir
umidade suficiente, algo que geralmente não é o caso em artefatos
arqueológicos [...]" [HUGHES, 2011, p.60]

Desde então uma coleção de novos métodos tomográficos, não destrutivos e com princípios completamente diversos, foram adicionados ao fluxo de pesquisa paleontológica e arqueológica. Daqui em diante serão tratados todos os métodos que podem ser aplicados em patrimônios (tratados a partir de então apenas por "peças", para incorporar os diferentes formatos e materiais comuns à essas áreas) paleontológicos, arqueológicos e etnográficos, todavia com menor ênfase nos mais improváveis de serem utilizados.

\subsubsection{Tomografia Computadorizada (Raios-X e Neutrons)}

O escaneamento por CT de Raio-X para a preservação e análise evoluiu nos últimos 30 anos, deixou de se caracterizar como experimental e exploratório, e passou a ser tratado como um campo sólido.

A tomografia axial computadorizada de Raios-X (TCR) existe em diversas resoluções e aplicações (tomografia por contraste de fase, baseada em síncroton - 
microtomografia, nanotomografia), porém o fator em comum entre elas é o de possuir uma fonte de Raios-X oposto a uma sequência de aparadores para detecção organizados em arco.

Figura 2: Geração de tomografias computadorizadas por Raio-X.

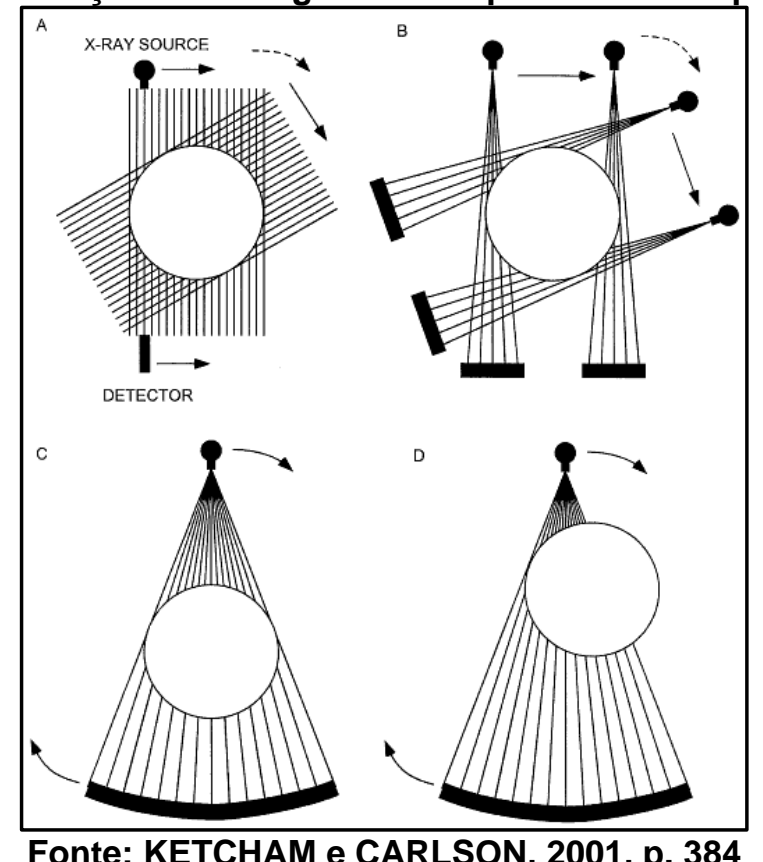

Assim, um feixe de Raio-X é lançado através da peça em questão e um grupo de dados é gerado. Esses dados são diretamente dependentes da densidade, composição e concentração do material da peça, visto que em densidades maiores a atenuação (Figura 2) também é maior. 
Figura 3: Tomografia de uma múmia egípcia que viveu entre 945 A.E.C. e 715 A.E.C. $\mathrm{Na}$ imagem é demonstrado o contraste entre o material do sarcófago, o ar, o linho e o espécime, bem como o ajuste de alcance dos pixels mostrados de uma imagem para outra.
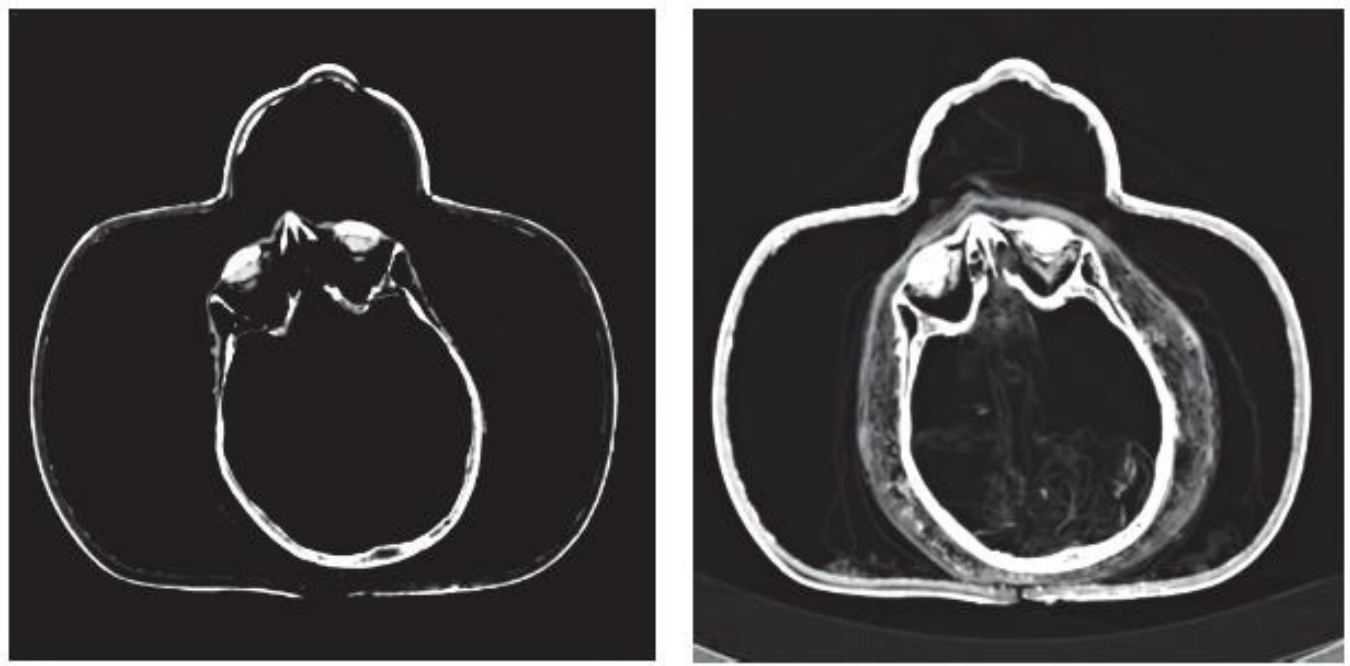

Fonte: HUGHES, 2011, p.63

$\mathrm{Na}$ TCR, os raios-x são gerados pela desaceleração de elétrons em um metal, [HSIEH, 2009], ou por síncrotron (acelerador de partículas), para atingir resoluções de microtomografia. Ela foi desenvolvida para geração de imagens em medicina, entretanto logo foi disseminada por vários outros campos, devido a sua capacidade de obter resultados na diferença entre materiais, que resultou em experimentações as quais potencializaram aplicações geológicas e industriais, por não precisarem ser limitadas à Raios-X de baixa energia (menores que $125 \mathrm{keV}$ ) [KETCHAM e CARLSON, 2001]. O uso de detectores menores em detrimento de grandes para maior exposição e captação possível, deixa de ser fator limitador na resolução obtida, pois a peça pode ser irradiada com feixes de maior nível energético. Influenciando também na compensação do declínio da captação, causado pelas superfícies reduzidas dos detectores [LAHA, BOWMAN e SOCHA, 2014].

Torna-se visível o alto nível de personalização do equipamento para obtenção de resultados específicos, por isso os escâneres são usualmente construídos para atender casos de uso, e, portanto, têm seus princípios minuciosamente detalhados e descritos em sua documentação.

Os prolegômenos da Tomografia de Neutrons (TN) se igualam aos da TCR, apenas com a substituição dos raios-x por neutrons livres. Apesar de um conceito simples, a TN exige instalações massivas para a geração de neutrons por fissão 
nuclear ou fragmentação de fontes de alto fluxo em aceleradores de partícula. Essa tomografia não é admitida como uma substituição ao TCR, apenas como uma alternativa complementar às peças difíceis de serem analisadas por este método [SUTTON et al, 2014]. Isso acontece devido aos princípios do neutrons, pois não interferem outros átomos por não possuírem carga, permitindo assim chegar diretamente ao núcleo, onde será espalhado ou absorvido, dependendo do átomo. Esse processo ocasiona na atenuação dos neutrons e claramente não está ligada a densidade do material, como o raio-x.

A TN pode fornecer resultados melhores que a TCR, em peças muito grandes, visto que os neutrons penetram a matéria muito mais facilmente que os raios- $x$, inclusive em metais pesados. Logo, onde é encontrada a limitação das imagens geradas pela atenuação dos raios- $x$, as geradas pela atenuação de neutrons podem ser mais eficazes [SCHWARZ et al, 2005].

\subsubsection{Tomografia Ótica e Ressonância Magnética}

Estes métodos são menos utilizados na arqueologia que os abordados até agora, isso se deve ao fato de serem mais indicados à materiais biológicos, principalmente a ressonância magnética.

Ela usa um campo magnético para mapear os núcleos de hidrogênio (em abundância em materiais biológicos devido a presença de água) por serem altamente sensíveis a este tipo de campo e assim gerar imagens de alta qualidade do interior, para isso o escâner precisa usar o campo magnético que ele gera para alinhar os momentos magnéticos dos núcleos de hidrogênio e aplicar um pulso de radiofrequência para perturbar esse alinhamento, permitindo que a bobina do escâner capte o sinal de RF emitido pelo objeto assim que o sinal RF aplicado cesse.

Já a tomografia ótica capta lâminas do objeto a partir de aplicações de raios luminosos no objeto, entretanto raios de diferentes intensidades, capacidades energéticas e faixas espectrais, podem ser utilizados para resultados adequados ao tipo de objeto. Esse método conta com várias abordagens como a microscopia confocal por laser (Confocal Laser-scanning Microscopy - CLSM), a microscopia confocal por estereoscopia de Raman, a tomografia por coerência ótica e a tomografia por projeção ótica. Os dois primeiros funcionam de forma similar, usam laser com 
comprimentos de ondas diferentes, uma para um modo em florescência e outro para um modo de reflectância, que através de uma lente objetiva capta um ponto de interesse, este posteriormente vem a ser equiparável a 1 pixel na imagem tomográfica final. A diferença entre eles está na precisão e tempo de captação, onde no primeiro será dependente do tipo de lente usada (a objetiva oferece até $10 \mu \mathrm{m}$ ), enquanto a Raman oferece até $1 \mu \mathrm{m}$ e necessita de várias horas para a captação de alguns pixels de informação. As duas últimas têm funcionamento análogo ao ultrassom, porém com substituem as ondas mecânicas por luz, elas não serão abordadas, visto que são exclusivamente utilizadas para materiais biológicos.

No contexto de herança cultural, a tomografia ótica (CLSM e Raman) é voltada principalmente para o registro de objetos translúcidos.

\subsection{MÉTODOS BASEADOS EM SUPERFÍCIE}

Os métodos baseados em superfícies estão categorizados como não destrutivos, visto que é definido como a captação em três dimensões da peça, porém não volumétrica [SUTTON et al, 2014]. Como o exemplo da múmia abordado no TCR sobre a capacidade de obtenção dos dados volumétricos da peça pôde mostrar [HUGHES, 2011], é inegável a importância do recolhimento de dados internos ao objeto sem a necessidade de haver degeneração física, principalmente para a paleontologia. Todavia não é fator fundamental ou mesmo pré-requisito para trabalhos envolvendo patrimônios virtuais.

\subsubsection{Digitalização Mecânica}

A digitalização mecânica se de trata método para a captação de dados tridimensionais utilizando material analógico para leitura da superfície. Os dados podem ser adquiridos através de um braço mecânico com sensores posicionais para medição de pontos na superfície, com a finalidade da geração de point cloud. Ou rotacionais, para captação de linhas aneladas, fechadas e semi-paralelas em torno da peça, úteis para a geração de superfícies por soluções vetoriais (como o non-uniform rationa $B$-Spline ou NURBS, existente em qualquer pacote de modelagem 3D). Ambos os modelos necessitam de registro posicional marcados na peça (diretamente nela ou em fitas transparentes), além da garantia de estabilidade (fixação por grampos ou por 
massa), por essa razão a digitalização sempre deve passar por algum tipo de recalibração [SUTTON et al, 2014].

Esses métodos permitem além de grande flexibilidade, por permitir a divisão da digitalização de uma peça muito grande em várias sessões de captação diferentes, embora a resolução esteja limitada a quantidade de linhas ou da distância posicional entre os pontos. Segundo Mallison, Hohloch e Pfretzschner (2009), dados gerados por esse método resultam em arquivos de formatos comuns e bem pequenos, se relativizados aos gerados por TCR ou escaneamento a laser, ideais para bancos de dados on-line.

Figura 4: Braço mecânico e posicionamento do fóssil.

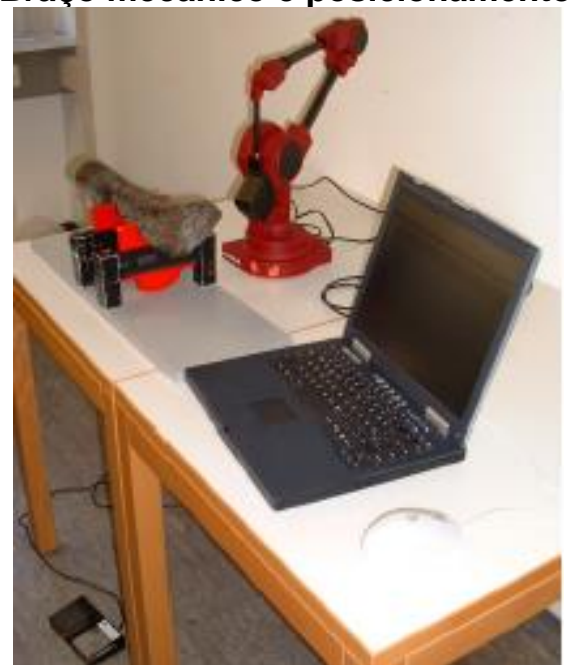

Fonte: MALLISON, HOHLOCH e PFRETZSCHNER, 2009, p.5.

\subsubsection{Fotogrametria}

A semente do viria a se tornar a fotogrametria atual, tem suas raízes em meados do século XVI, juntamente como a incorporação da perspectiva às pinturas e afrescos renascentistas. A partir dela, Leonardo da Vinci começou a estudar a natureza da compreensão tridimensional do mundo, e desta forma fomentou o estudo do campo da perspectiva como geometria projetiva. Não levou muito tempo para que cientistas adotassem as leis da perspectiva para criar novos instrumentos, contudo apenas em 1759 que Johan Heinrich Lambert desenvolveu os princípios matemáticos de uma imagem em perspectiva usando seccionamento espacial para achar um ponto do qual a imagem é gerada, para que finalmente em 1883 a relação entre estes princípios e a fotogrametria fosse desenvolvida [DOYLE, 1964]. 
Desde então, a fotogrametria passou um século em mudanças sutis e sendo usada como método de mapeamento topográfico através do acoplamento de câmeras a aeronaves para reconhecimento aéreo (técnica extensamente utilizada nas grandes guerras). Porém, essa figura muda completamente com a incorporação de computadores ao processo, aumentando consideravelmente a precisão e rapidez do processo. Logo novas aplicações começaram a ser exploradas, inclusive segundo Sutton et al (2014): "Isso culminou no aparecimento da fotogrametria digital nos anos 1980, seguindo a invenção da câmera digital. Aplicações modernas incluem cartografia, medicina, ciência forense, arqueologia e paleontologia”3.

A fotogrametria utiliza da triangulação de pontos homólogos em múltiplas imagens de conteúdo similar, para a posterior reconstrução tridimensional da superfície do objeto. As imagens utilizadas possuem geralmente informações de cor, iluminação [DEBEVEC, 2012] e textura, e esses elementos podem ser usados para complementação das informações captadas, adicionando informações de cor diretamente no point cloud ou posteriormente como textura, na peça já reconstruída.

A distância entre a câmera e o objeto subdivide a fotogrametria em dois, a Aérea, onde a câmera é colocada em uma aeronave e posicionada ortogonalmente relativo ao chão distanciado por no máximo 300m, é importante para o mapeamento de grandes terrenos e na criação de modelos de elevação também importantes para a digitalização de sítios de patrimônios culturais (arqueológicos, paleontológicos, antropológicos, ...), apesar de exigir equipamento de alto custo, o uso de drones e câmeras de baixo custo e relativamente alta resolução têm possibilitado a coleta de modelos 3D de mais de 80 sítios ao redor do País de Gales (Reino Unido), bem como muitos outros dados como mapas, fotos, condições climáticas e outros [MILES et al, 2015]. A outra é a de curto alcance, nela o equipamento necessário é mais básico, consistindo em pelo menos uma câmera digital e um computador com um software adequado, é o método para captação de modelos $3 \mathrm{~d}$ mais econômico e de maior portabilidade. A qualidade e resolução da fotogrametria está ligada diretamente a quantidade de imagens usadas como dados de entrada.

Os pontos análogos encontrados pelo processo, em conjunto passam a formar uma nuvem de pontos ou point cloud, quanto maior a densidade da nuvem de pontos

\footnotetext{
${ }^{3}$ Grifos do autor
} 
do objeto em questão, maior será a resolução, portanto a evidenciação e enquadramento do objeto pode causar influência na precisão do modelo.

A fotogrametria é bem mais rápida e barata que o escaneamento a laser e pode ser capaz de produzir resultados tão bons quanto. Entretanto, como a resolução depende diretamente da quantidade de imagens obtidas da peça, e seguro afirmar que peças mais complexas necessitam de maior resolução e logo sua natureza interfere na adaptação do fluxo de captação. Não apenas isso, como esse método depende da medição de pontos em comum de uma imagem para a outra, é fundamental que o objeto em evidencia tenha imagens sobrepostas idealmente em $66 \%$ e esteja presente em pelo menos 3 imagens [SUTTON et al, 2014 apud FALKINGHAM, 2012].

\subsubsection{Distância Por Alcance Ótico}

Os sensores óticos por distância podem medir a profundidade de pontos em um dado objeto, isso ocorre sem qualquer contato com o objeto através de feixes luminosos, logo seus resultados sempre contêm informação tridimensional. Estes sensores são baseados em seis princípios: radar, triangulação, técnicas de Moiré interferometria holográfica, foco e difração [CANTONI, LEVIALDI e ROBERTO, 1997].

Os radares podem efetuar a medição da distância através do tempo que o pulso é refletido pela superfície (time-of-flight) ou pela diferença de fase entre os sinais enviados e recebidos, para isso os sensores baseados em laser são utilizados.

\subsubsection{Laser}

Dos métodos de baseados em superfície, o laser é o mais difundido por entre especialistas em herança virtual, é tradicionalmente utilizado em conjunto com a fotogrametria para complementar com texturas de alta qualidade [Shott, 2014]. Isso acontece porque ele oferece uma boa razão entre portabilidade, precisão e custo.

O escaneamento a laser pode se dar pelo princípio de radar onde um pequeno pulso de laser é emitido e uma vez refletido do objeto ele é detectado por um sensor. Podemos determinar a distância entre o escâner e o objeto através do tempo que o laser (3,3 x 10-12/ mm) leva para atingi-lo e retornar, dividido por dois e multiplicado 
pela velocidade da luz, este processo é denomidado time-of-flight e pode prover alta densidade de pontos por segundo. Em adição, a medição por mudança de fase herda o mesmo princípio, porém ao invés de medir com base no tempo de retorno, usa a comparação entre as fases nos dois momentos [ALONSO et al, 2011]. Ambos os casos podem oferecer um nível de precisão bastante alto e alcances de até $100 \mathrm{~m}$, variando de acordo com as especificações do escâner.

O posicionamento de um ponto no objeto pode ser também encontrado através da triangulação de um feixe lançado e tendo a sua reflexão captada por um sensor com a capacidade de medir sua intensidade e posição. A partir daí uma varredura pela superfície do objeto é realizada movendo a luz ou o objeto em si. Os escâneres laser são caso específico do uso deste princípio e podem ser classificados entre os que captam um ponto por vez (single point) e os captam a profundidade dos pontos em uma linha projetada (plane of light) que é traduzida em uma curva 3D [CANTONI, LEVIALDI e ROBERTO, 1997].

\subsubsection{Fotometria}

Métodos por fotometria podem ser definidos como todos aqueles que usam luz ou sensores luminosos para medir a distância através da intensidade e/ou padrão. Abrange então métodos como o de luz estruturada, silhueta e foco. Diferem dos métodos laser apenas pelo nível energético do feixe luminoso utilizado.

Para isso a triangulação está geralmente associada ao método de luz estruturada, onde uma câmera capta o padrão luminoso projetado do objeto e com base na posição do emissor e da câmera é possível inferir a profundidade de cada ponto com precisão de alguns micrômetros com alcance de alguns metros, dependendo diretamente do equipamento utilizado. Porém depende que a geometria da peça seja conhecida. Caso uma linha seja projetada, em detrimento de um padrão, a profundidade pode ser captada através da silhueta formada, um método similar ao plane of light na triangulação com laser, porém a amostragem por pixel [CANTONI, LEVIALDI e ROBERTO, 1997].

Um método fotométrico menos utilizado é o de captação através de mudanças no sensor receptor, como o de mudança focal, em que o alvo é exposto à uma câmera calibrada, esta então tem seu ponto focal dinamicamente variado ao longo da 
exposição, resultando então em um conjunto de quadros que relacionados entre si pode gerar um vídeo a partir dos mapas de profundidade de cada quadro.

Estes métodos, bem como o de mudança focal, resultam em mapas de profundidade que podem ser utilizados para a geração de point clouds.

\subsection{RECONSTRUÇÃO}

Segundo Rahman e Smith (2014), todas as tomografias não destrutivas são adequadas a fósseis de vertebrados, e a aquisição pode levar de minutos a horas. Por outro lado, a fotogrametria possui região de interesse limitada a resolução e foco das imagens, e, portanto, não possui um limite definido para a resolução e ainda assim levar de minutos a horas para uma captação. Assim, é importante seguir critérios para que seja escolhido o melhor sistema para o cumprimento dos objetivos da peça capturada.

Tabela 1: Critérios para a escolha do sistema de digitalização adequado.

\begin{tabular}{ll}
\hline № & \multicolumn{1}{c}{ Critério } \\
\hline 1 & Custo \\
\hline 2 & Tipo de material sujeito a digitalização \\
3 & Tamanho da peça sujeita a digitalização \\
\hline 4 & Portabilidade do equipamento \\
\hline 5 & Precisão do sistema \\
\hline 7 & Aquisição da textura \\
\hline 8 & Habilidades pré-requisitadas \\
9 & Concordância dos dados produzidos com os padrões \\
\hline
\end{tabular}

Fonte: PAVLIDIS et al, 2007, p.94

\subsubsection{Dados de superfície}

Pode ser incluído neste contexto, a modelagem manual. Esta consiste na reconstrução da superfície por artista especialista, usando fotos, diagramas e croquis como dados suficientes para reconstrução.

A superfície é em geral reconstruída a partir do point cloud denso obtido através do método de captura aplicado e então usado o algoritmo de rastreio de Poisson [KAZHDAN e HOPPE, 2013]. 
Figura 5: Fluxo de geração de modelos a partir de dados de superfície

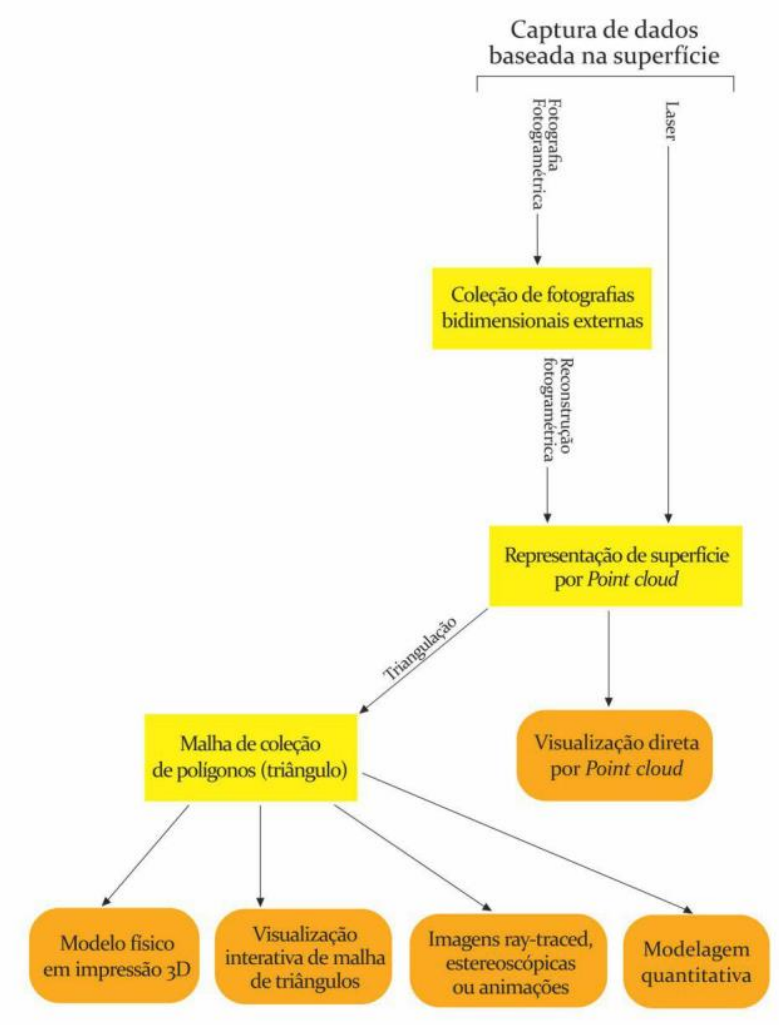

Fonte: Adaptado de SUTTON et al, 2014, p.164

\subsubsection{Métodos de Visualização}

Dentre os métodos de visualização mais comuns, estão as superfícies por malhas de triângulos, elas costumam ser obtidas por isosurfacing ou point cloud, o que pode significar quantidades massivas de triângulos por malha. Isso pode tornar o processo de visualização bem complicado em computadores de baixo a médio desempenho, por essa razão alguns algoritmos podem ser usados para a redução poligonal da malha, entretanto podem ocasionar em artefatos. As malhas de triângulos podem gerar malhas poligonais mais complexas, muito usadas em "[...] ciência, engenharia e medicina, foi seu uso na indústria de videogames que tem sido o direcionador para as tecnologias envolvidas." [SUTTON et al, 2014].

A renderização direta de point clouds, apesar de menos interessante visualmente, pode fornecer uma visualização mais rápida do objeto, sem precisar da visualização de dados de superfície. O lado negativo é que necessita de aceleração por hardware, o que resulta em uma experiência mais lenta.

Os dois métodos mencionados até agora podem ser base para a impressão tridimensional, exigindo apenas algum tratamento de redução poligonal na malha. $A$ 
fidelidade é dependente da qualidade da captura 3D, da reduzida quantidade de artefatos gerados pela redução, do material em que está sendo impresso e a resolução que a impressora pode comportar.

\subsection{TÓPICOS SOBRE MUSEOLOGIA E ARQUEOLOGIA}

A museologia é uma ciência que atua como identificadora de referências culturais a partir de bens arqueológicos, iluminando ações preservacionistas ao mesmo tempo que permeia processos comunicacionais educativos. Logo, a musealização pode ser entendida como a elaboração de um sistema estético para criar significados [SHANKS e TILLEY, 1992, apud BRUNO, 2014].

Essa ciência tem como objeto de estudo o fato museológico (ou museal), que trata-se da relação entre o homem e o objeto, que acontece através do fenômeno museológico e o reconhecimento dos processos de musealização. No caso do fenômeno museológico, é referenciada a construção de informações em três etapas, a transferência de conhecimento, a catalogação ou registro do identificado e a sistematização das ideias. Já o reconhecimento dos processos de musealização consiste em assumir os caminhos percorridos na investigação do indicador da memória.

A musealização da arqueologia surge a partir do uso de vestígios arqueológicos como indicador de memória para a expansão da compreensão da territorialidade, logo a divisão dos sentidos e significados é definida pela área (local, regional e nacional), por sua importância e o país em que sua pesquisa é feita, para fim de integrar os bens arqueológicos com outros bens. O Bem Arqueológico é um vestígio ou indicador da memória, com o olhar científico, a temporalidade, territorialidade, a política científicocultural e a preservação.

A musealização da arqueologia embasa as ligações para aproximação dos vestígios arqueológicos com a averiguação de metodologias de salvaguarda e comunicação dos bens patrimoniais. Onde por patrimônio entende-se "o conjunto seletivo e preservado de bens materiais e imateriais, fruto das relações que os Homens estabelecem, ao longo do tempo, com o meio ambiente e em sociedade, e suas respectivas interpretações" [Bruno, 2014]. A musealização da arqueologia certifica a incorporação de significado às relações entre homem e patrimônio, bem 
como futuras relações embasadas nestas. Os acervos arqueológicos podem estar dispostos em museus de história natural ou de artes (descontextualização, o objeto pelo objeto), onde o registro começou a acontecer desde o século XVIII, e os objetos arqueológicos obtidos através de saques e/ou resgates.

Por tratar da ressignificação do patrimônio, a museologia tem caráter antropofágico marcado por choques entre passado e presente, e extremamente vulnerável a oscilações políticas, infraestrutura e criação/manutenção de uma imagem cultural. Assim, é mantida uma política cultural e preservacionista no País, em que a sociedade é excluída do processo de preservação. Porém, por outro lado o Programa de Aceleração do Crescimento (PAC) influenciou na aceleração da avaliação arqueológica de grandes obras com impactos ambientais, algo que consequentemente aumentou a demanda por profissionais e paralelamente forneceu oportunidades de acesso a sítios inacessíveis anteriormente. Nesse contexto, a autorização é dada primeiramente para o profissional ou instituição, e assim o acesso é liberado para que então o destino do material seja decidido.

Esse aumento na demanda gerou a acervos demasiadamente grandes e em muitos casos dispersos. Nessa linha, o IPHAN fez um levantamento sobre a dispersão dos acervos no Brasil inteiro, os quais estavam depositados em fábricas, igrejas, instituições de pesquisa, etc. Logo, as instituições de pesquisa não podem ignorar essa realidade, assim algumas ideias surgem para gerenciamento desses acervos como depósitos de pesquisa onde o material fica guardado e sistematizado, para fins de acesso por instituições de pesquisa. Por outro lado, com a baixa e a paralisação dos empreendimentos, consequentemente há uma estagnação dos trabalhos em musealização, algo que desde 2009 foram percebidas baixas nas portarias de pesquisa (permissões).

Os museus nacionais não consideravam o período pré-colonial e as linhas de pesquisas arqueológicas possuíam linhas importadas. Os vestígios eram pesquisados estratigraficamente (no Brasil) ou em área, como exemplo da linha antropológica na França. Apenas na década de 80 os dois lados são considerados. Entretanto, o IPHAN ainda reforça esse estigma, visto que apesar da modernização desse foco ressaltando o ser brasileiro, ainda foi uma elite cultural que generalizou e simplificou o nacional e deixou à deriva o regional. 
A museologia está à parte da neutralidade e tem a sua relação geralmente dependente das políticas públicas e escolha seletiva de patrimônio para visibilidade. Ela sofre com a chamada estratigrafia do abandono, e acentuada pela fragilidade das instituições. Por outro lado, a musealização da arqueologia assume foco regional graças às exigências da legislação ambiental, e ainda assim essa estratigrafia pode ser relacionada aos bens pré-coloniais.

A herança da arqueologia musealizada encontra impasse quando relacionada com a musealização da arqueologia, principalmente pelas tendências da cadeia operatória a qual a arqueologia musealizada já sofreu, e logo já agrega a parcialidade do processo. É a memória já construída e ressignificada por ações que podem variar de acordo com as políticas públicas, interpretações, e reflexões mais aprofundadas.

A multivocalidade é um fator relevante para noção de pertencimento, onde a regionalização dos museus tem acompanhado 0 aumento das pesquisas arqueológicas, assim as trocas culturais acontecem com maior frequência através da participação das comunidades nas ações museológicas. Entretanto, a implementação de um eixo estrutural que evite a função de depósito pelo museu. Os trabalhos em educação patrimonial são focados e amparados pela legislação, mas não são integrados com ações museais.

A museologia incorpora a noção de território, em referência não apenas à lugar com a apropriação das paisagens culturais do passado e atuais, mas também à percepções geradas a partir de diferentes conhecimentos. Na musealização da arqueologia contemporânea, essa perspectiva pode ser chamada de acervos divididos.

\subsection{RECONSTRUÇÃO MUSEALIZADA}

Weber (2014) identifica os interesses em comum entre pesquisadores de antropologia, arqueologia e paleontologia, analisando primariamente métodos para o trabalho de campo, ele então faz um paralelo com a antropologia virtual (Virtual Anthropology - VA), que pode ser estendida a arqueologia e a paleontologia, e a divide em seis áreas: Digitalização (captação dos dados tridimensionais), exposição (malhas de superfícies dos objetos ou volume), comparação (descrição matemática da morfologia das peças), reconstrução (correção de imperfeições da peça, como 
desgaste temporal, deformação, partes faltando, montagem de objeto com peças separadas, ...), materialização (aplicação dos métodos de visualização, em evidência a impressão 3D) e compartilhamento (colaboração).

Cada uma dessas áreas cumpre com requisitos operacionais para a arqueologia, como a facilidade e possibilidade de acesso por toda a estrutura do objeto e concorrentemente manter uma alta densidade de dados para análises quantitativas mais precisas. Segundo Weber (2014), aliar a captura de dados visando tecnologia 3D com cada uma dessas áreas deixa o trabalho de campo mais prolífico, visto que é preciso manter o máximo de dados possíveis possibilitando assim expandir posteriormente o número de opções para manuseio de dados, estatística, visualização, bem como também o aumento da precisão de medições. Relacionando então cada uma dessas áreas operacionais com a arqueologia e considerando elementos específicos ao contexto nacional, a exposição perde o seu sentido em capturas de superfícies visto que é um processo de relação e análise entre a superfície e o volume, a reconstrução é do ponto de vista da arqueologia e se trata da reconstrução de áreas ou aspectos dos elementos para corresponderem à como eram, em detrimentos de como estão atualmente, este é um segmento que apesar de pequeno é bem presente em análise de artefatos. O compartilhamento também é deixado de lado, onde apesar de ser uma prática lógica para a análise de um volume muito grande de peças, é uma prática pouco explorada devido a questões de incompatibilidade de tamanho de equipe para a quantidade de peças e questões legais, como a Lei da Arqueologia 4 (lei no 3.924 de 26 de julho de 1961) que reconhece qualquer sítio, peça ou monumento arqueológico encontrados em território nacional passam estar sob guarda da União. Com isso podemos limitar as áreas operacionais à digitalização, como a captura dos pontos de superfície ou fotos e reconstrução tridimensional, à comparação, descrição discreta das peças ou relação com dados de terceiros sobre a mesma peça, e a materialização por métodos de visualização.

\subsubsection{Métricas de Qualidades e suas aplicações}

A partir destas áreas operacionais podemos relacioná-las a duas definições do estado de qualidade. A primeira é a adequabilidade para o uso de um artefato

4 Diário Oficial da União. LEI № 3.924, DE 26 DE JULHO DE 1961. <http://www.planalto.gov.br/ccivil_03/leis/1950-1969//3924.htm>. Acessado em <fevereiro de 2018> 
digitalizado, que pode ser definida através da coleta de parâmetros únicos ao mesmo e assim identificar o modelos corretamente captados de outros considerados incorretos, e o segundo se trata da conformidade com os requisitos, como expõe Neamtu et al (2014), que ainda descreve a precisão, a rastreabilidade a compatibilidade e precisão de textura, como meios de quantificar a qualidade de artefatos digitais. Considerando assim que o objeto de análise é a malha gerada, exclui assim as cores e texturas, podemos incorporar a precisão, a rastreabilidade e compatibilidade.

\subsubsection{Precisão}

A precisão pode ser quantificada através da comparação da distância entre os pontos das malhas captadas pelo processo de controle (laser) com as captadas pelos outros processos. Em todos os casos o objeto sofre perdas no nível de fidelidade quando comparado com o objeto real, entretanto a digitalização à laser adotada possui um índice de erro muito baixo, entre $100-300 \mu \mathrm{m}$, tido como irrelevante para os métodos de materialização (impressão $3 \mathrm{D}$ e visualização digital) voltados a documentação e educação patrimonial. Adotando-a então como controle, as contrapartes digitalizadas através de outros métodos seguem então um processo para determinar o desvio entre elas, e para isso são definidos os passos a seguir:

- Captura dos dados;

- Os point clouds são importados para medição em um software de processamento de point clouds;

- Os pontos são alinhados utilizando os métodos de pontos pares e registro fino;

- Calcular as distâncias entre os point clouds.

O resultado é o desvio dos objetos escaneados pelos métodos propostos com o método a laser, onde esse desvio é relacionado ao ponto mais distante entre as peças. Por essa razão a diferenças entre os variados métodos de captura podem ser mostradas através de mapas de desvio. 


\subsubsection{Rastreabilidade}

A rastreabilidade do objeto pode ser definida como a capacidade de manter controle sobre os passos necessários para a criação do mesmo, desde a captura até a reconstrução da malha. Neamtu et al (2014) pontua como a gravação de cada etapa e seus respectivos resultados, para fim de tornar os resultados replicáveis.

Entretanto, em detrimento da escolha desses autores em usar software CAD [BUNA et al, 2014] para registrar a evolução dos processos na malha, visto que softwares externos teriam que ser eliminados do processo, foi escolhido um registro manual de cada etapa descritos com detalhes em cada processo que se estende ao conjunto formado por dados de captura (quantidade e tempo), criação dos point clouds e criação da superfície [HESS et al, 2015].

Além disso este item também está ligado com a habilidade necessária para a captura, e logo esse conjunto de dados incorporam o tempo de captura para cada peça e complexidade da linha de produção da peça.

\subsubsection{Compatibilidade}

Este item define a acessibilidade de cada artefato digital gerado no contexto de materialização do objeto, onde são analisadas a plataforma de visualização e a densidade poligonal. A primeira pode ser definida como impressão 3D ou visualização digital, e para ambas a escolha adequada do formato 3D é imprescindível, visto que dependendo do escolhido algumas informações podem ser perdidas. A tabela a seguir mostra as vantagens e desvantagens de cada formato comum:

Tabela 2: Vantagens e desvantagens de cada formato de arquivo 3D. Estão grifados os defeitos mais críticos.

\begin{tabular}{|c|c|c|}
\hline Formato & Vantagens & Defeitos \\
\hline $\begin{array}{l}\text { OBJ } \\
\text { (MURRAY } \\
\text { e } \\
\text { VANRIPE } \\
\text { R, 1996) }\end{array}$ & $\begin{array}{l}\text { É um formato simples, } \\
\text { amplamente utilizado, se trata } \\
\text { de um padrão para representar } \\
\text { malhas poligonais em ASCII. } \\
\text { Guarda um escopo ilimitado de } \\
\text { cores, tamanho e número de } \\
\text { imagens. }\end{array}$ & $\begin{array}{l}\text { Não é comprimido por padrão, mas pode ser } \\
\text { comprimido. Sua contraparte em binário usa a } \\
\text { extensão .MOD, entretanto é pouco utilizada. } \\
\text { Não suporta materiais e informações de } \\
\text { iluminação. }\end{array}$ \\
\hline
\end{tabular}

${ }^{5}$ Murray, J. D. e VanRiper, W. 1996. Graphic File Formats, Second Edition. Editora O'Reilly \& Associates. Segunda edição. 


\begin{tabular}{|c|c|c|}
\hline $\begin{array}{l}\text { STL e } \\
\text { PLY }\end{array}$ & $\begin{array}{l}\text { Formatos simples, usados } \\
\text { amplamente e compreendidos } \\
\text { pela maioria dos softwares. } \\
\text { Pode estar em ASCII (legível) } \\
\text { ou em binário (linguagem de } \\
\text { máquina). }\end{array}$ & $\begin{array}{l}\text { Não suporta múltiplos objetos; não possibilita } \\
\text { incorporação de metadata; arquivos STL em } \\
\text { ASCII são grandes demais; arquivos binários } \\
\text { são pequenos, mas não suportam compressão; } \\
\text { arquivos STL não guardam informações de cor } \\
\text { por vértice; arquivos PLY podem incluir atributos } \\
\text { fora do padrão que nem todos os softwares } \\
\text { podem compreender. }\end{array}$ \\
\hline DXF & $\begin{array}{l}\text { Formato simples, usados } \\
\text { amplamente e compreendidos } \\
\text { pela maioria dos softwares. É } \\
\text { legível. Suporta múltiplos } \\
\text { objetos e nomeados. }\end{array}$ & $\begin{array}{l}\text { Os arquivos são normalmente muito grandes } \\
\text { (maior que o STL); campos limitados para } \\
\text { incorporação de metadados (por exemplo, sem } \\
\text { campos para representar corretamente a cor } \\
\text { dos objetos). }\end{array}$ \\
\hline 3DS & $\begin{array}{l}\text { Formato flexível, compacto e } \\
\text { permite metadados. }\end{array}$ & $\begin{array}{l}\text { Limitação de } 65536 \text { triângulos por malha; não } \\
\text { dispõe de facilidades para marcação arbitrária } \\
\text { de metadados de objetos; não é legível. }\end{array}$ \\
\hline $\begin{array}{l}\text { VRML / } \\
\text { X3D }\end{array}$ & $\begin{array}{l}\text { Formato muito utilizado, porém } \\
\text { não tanto quanto STL e DXF; o } \\
\text { VRML (iteração antiga) é } \\
\text { legível e possui algumas } \\
\text { facilidades para metadados; } \\
\text { X3D fornece arquivos mais } \\
\text { compactos e binários em troca } \\
\text { da legibilidade humana. }\end{array}$ & $\begin{array}{l}\text { Arquivos VRML em particular são muito grandes } \\
\text { (maiores que DXF); softwares de visualização } \\
\text { têm baixa performance (e softwares para X3D } \\
\text { são escassos); não escalonam corretamente à } \\
\text { modelos com alta contagem de triângulos; não } \\
\text { dispõe de facilidades para marcação arbitrária } \\
\text { de metadados de objetos. }\end{array}$ \\
\hline PDF / U3D & $\begin{array}{l}\text { Dados de PDFs tridimensionais } \\
\text { (incorporando U3D) podem ser } \\
\text { visualizados no Adobe Reader } \\
\text { gratuito, já disponibilizado na } \\
\text { maioria dos computadores; } \\
\text { boas facilidades para } \\
\text { metadados; tamanho do } \\
\text { arquivo relativamente pequeno. }\end{array}$ & $\begin{array}{l}\text { Quantidade de softwares visualizadores limitada } \\
\text { (essencialmente apenas o Adobe Reader) e que } \\
\text { faltam opções fundamentais (por exemplo, } \\
\text { visualização em estéreo), não suporta a } \\
\text { exportação de dados, e tem baixa performance } \\
\text { em modelo complexos; poucas ferramentas } \\
\text { gratuitas de exportação para geração de } \\
\text { arquivos; falta de transparência e legibilidade do } \\
\text { formato de arquivo. }\end{array}$ \\
\hline $\begin{array}{l}\text { FBX } \\
\text { (FilmBox) }\end{array}$ & $\begin{array}{l}\text { Formato flexível; Pode estar } \\
\text { em ASCIl (legível) ou em } \\
\text { binário (linguagem de } \\
\text { máquina), o SDK suporta } \\
\text { leitura e escrita de ambos. }\end{array}$ & $\begin{array}{l}\text { Possui um SDK em C++ capaz de converter } \\
\text { arquivos para FBX ou de FBX para outros, } \\
\text { também pode efetuar leitura e escrita; apesar de } \\
\text { proprietário, possui sua descrição exposta; } \\
\text { possui capacidade de incorporação de } \\
\text { metadados ajustável com controle dos } \\
\text { cabeçalhos. }\end{array}$ \\
\hline $\begin{array}{l}\text { VAXML } \\
\text { (SUTTON } \\
\text { et al, } \\
2012)^{6}\end{array}$ & $\begin{array}{l}\text { Apropriado } \\
\text { paleontologicamente e um } \\
\text { sistema de metadados que é } \\
\text { legível e writable; usa formatos } \\
\text { de arquivos amplamente } \\
\text { compreendidos (STL/PLY) para } \\
\text { as malhas de triângulos; é } \\
\text { extendível à conjunto de dados } \\
\text { de point clouds através do uso } \\
\text { de arquivos PLY. }\end{array}$ & $\begin{array}{l}\text { Os conjuntos de dados são multi-arquivos (o } \\
\text { arquivo VAXML acrescido de um ou mais } \\
\text { arquivos STL/PLY), complicando a entrega; não } \\
\text { é tão compacto quanto alguns formatos; falta de } \\
\text { visualizadores diretos (é limitado ao } \\
\text { SPIERSview) - porém, apesar de arquivos } \\
\text { STL/PLY puderem ser importados para qualquer } \\
\text { software, metadados não. }\end{array}$ \\
\hline
\end{tabular}

Fonte: Adaptado de Sutton et al (2012, apud Sutton, 2014)

${ }^{6}$ Sutton, M. D., Garwood, R. J., Siveter, D. J., et al. (2012) SPIERS and VAXML; a software toolkit for tomographic visualization and format fo virtual specimen interchange. Paleontologia Electronica. Volume 15, Edição 2, 5T. 
Essa escolha também interfere diretamente na visualização do artefato dependendo de sua densidade poligonal, visto que alguns não suportam malhas muito densas e outros não são corretamente lidos em plataformas web ou mesmo em impressão 3D. 


\section{$4 \quad$ APLICAÇÕES EM TRABALHOS CORRELATOS}

No Brasil o uso de diferentes técnicas e recursos para o arquivamento de patrimônio está em ascensão, algumas iniciativas podem ser pontuadas, como a do trabalho de pesquisa e interpretação dos naufrágios na Baia de Todos Santos (Bahia) onde Torres et al [2017, p.107] integraram ferramentas digitais a este contexto. Através de "um fluxo de trabalho que tem como base o uso da fotogrametria para a criação de modelos digitais tridimensionais em escala real de sítios e artefatos”.

Concluem então que meios digitais permitem maior colaboração e grande quantidade de dados, o que fornece a capacidade de performar estudos mais robustos. Até mesmo enriquecer processos educomunicativos.

Outra aplicação de impacto fora a preservação digital e reconstrução para fins educacionais da cidade de Conímbriga (Portugal). Esta foi um importante centro durante o império romano, no entanto já não é mais habitada desde o século IX e em decorrência disso ela é bastante afetada pela erosão natural [GONÇALVES, RODRIGUES e HIPÓLITO-CORREIA, 2014].

Para isso os autores propuseram a reconstrução manual e procedimental para a modelagem dos objetos que o sítio contém e a materialização através da web usando ThreeJS, biblioteca javascript para apresentação de objetos 3D no browser. Neste caso a reconstrução manual foi escolhida com base na inviabilidade de densidade dos modelos que o processo de fotogrametria e laser poderiam gerar, por outro lado o projeto comtempla a capacidade de adicionar o esse fluxo futuramente. Visto que toda a cidade é criada proceduralmente utilizando elementos criados manualmente, ela pode ser visualizada pelo browser então é fundamental tenha baixa densidade poligonal. 


\section{METODOLOGIA}

A seguir serão abordados todos os métodos escolhidos para a pesquisa. Iniciando com a escolha dos objetos, os métodos de captura, os processos de construção da malha, validação quantitativa e sua visualização para interações humano-computador.

Figura 6: Etapas de metodologia

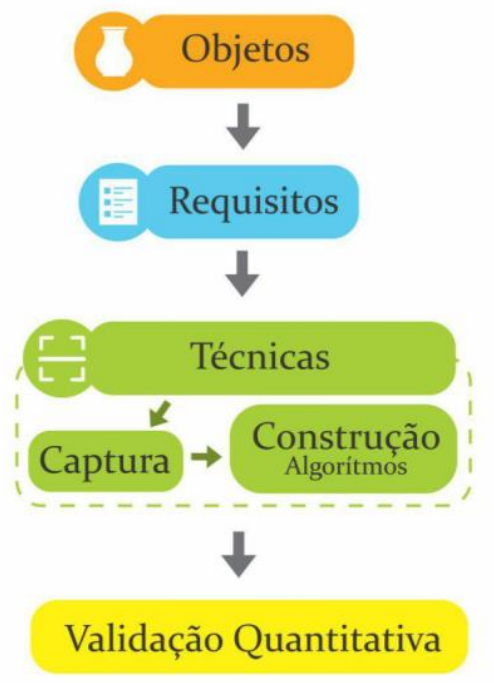

Fonte: Autor, 2016.

\subsection{DEFINIÇÃO DOS OBJETOS}

Os objetos foram escolhidos após entrevista com especialistas (Zanettini Arqueologia), os quais trabalhavam na gestão do patrimônio arqueológico para o licenciamento da obra do Plano de Aceleração do Crescimento do Governo Federal da Ferrovia Transnordestina, malha ferroviária que interliga os estados de Pernambuco, Ceará e Piauí, e pelo porte do empreendimento, que conta com 1.700 quilômetros, indica um caráter reorganizador do espaço.

A grande maioria dos artefatos encontrados podem ser resumidos a armas/ferramentas e contêineres, onde apesar de haver alguns registros arqueoantropológicos e paleontológicos, os de maior valor histórico são os primeiros e por essa razão suas peças de referência estão entre as mais analisadas. Nos mais de 550 sítios arqueológicos identificados, aproximadamente 95 mil peças foram resgatadas, das quais 28.041 foram por esses mesmos especialistas. Assim, para criar um ponto de vista qualitativo que favoreça a construção da história, eles criaram 
vários lotes, que neste contexto pode ser triangulado como coleções de dados (artefatos físicos), com peças de referência selecionadas para melhor representar cada sítio, considerando cor, material, forma e pontos de interesse (individualidades da peça). Por exemplo, a ponta de flecha (Figura 7) mostra claramente os sinais de uso, tem também desgaste aparente, porém ainda assim não está em condições que incapacite a percepção de sua forma, logo foi cotada para servir de peça de referência para melhor identificar o conteúdo de sua coleção. Em análises e estudos de contextos isso se mostrou uma técnica bem eficaz, porém para processos de comunicação e educação patrimonial a quantidade de peças por coleção ainda foi bastante elevada, logo o mesmo processo para a escolha de uma peça de referência foi adotado novamente para evitar a musealização e implantação de centenas de peças para esse fim.

Assim para este trabalho, cada objeto fora definido de acordo com a ordem de relevância das peças para todo o conjunto de coleções. E com o apoio dos especialistas, 4 peças foram escolhidas dentre todo o catálogo:

Figura 7: Ponta de flecha (ver anexos)

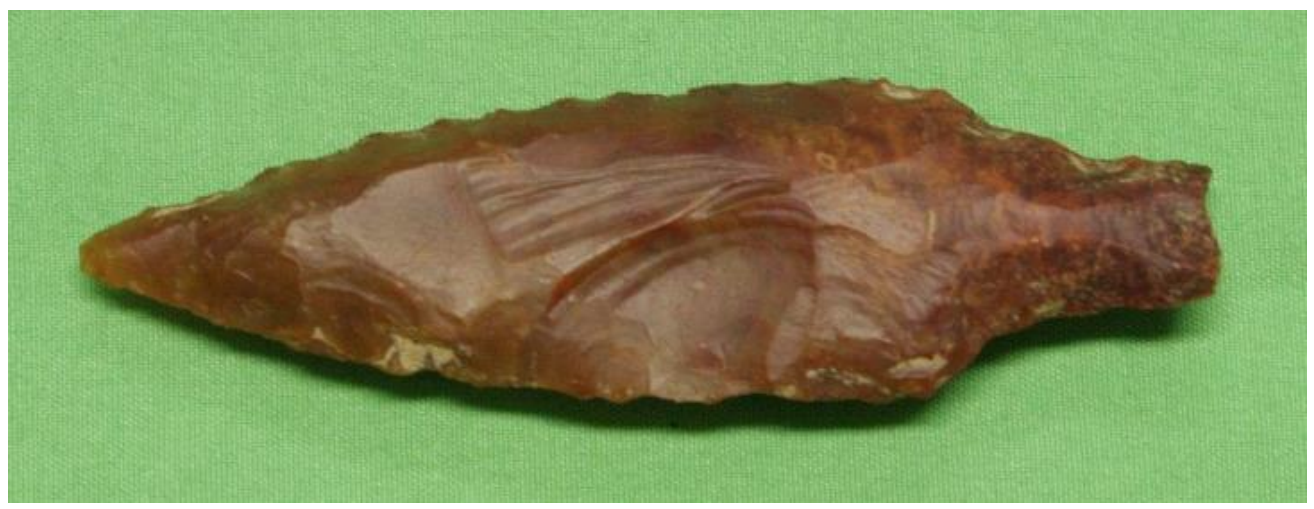

Fonte: Autor, 2016. 
Figura 8: Borda de vaso (ver anexos)

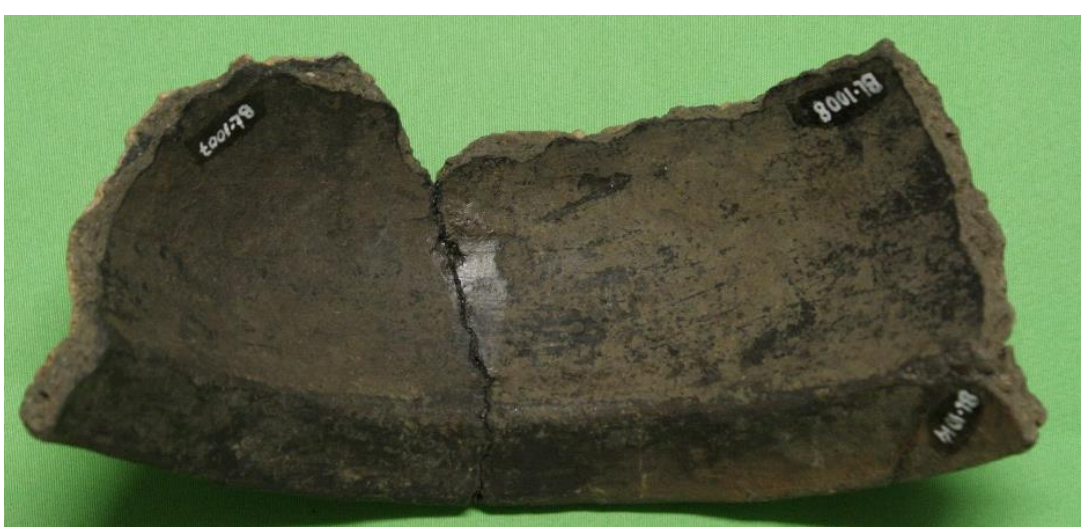

Fonte: Autor, 2016.

Figura 9: Machadinha (ver anexos)

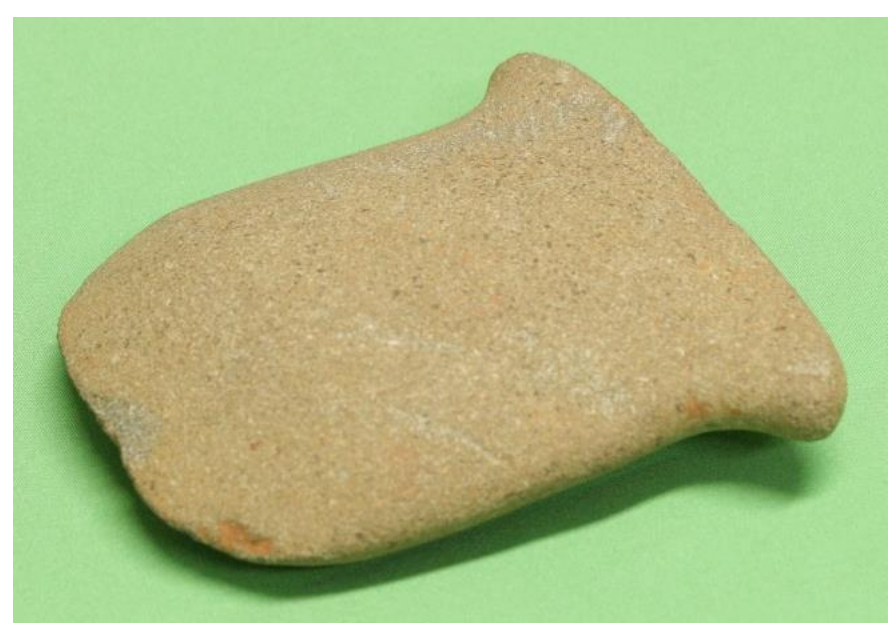

Fonte: Autor, 2016.

Figura 10: Vaso (ver anexos)

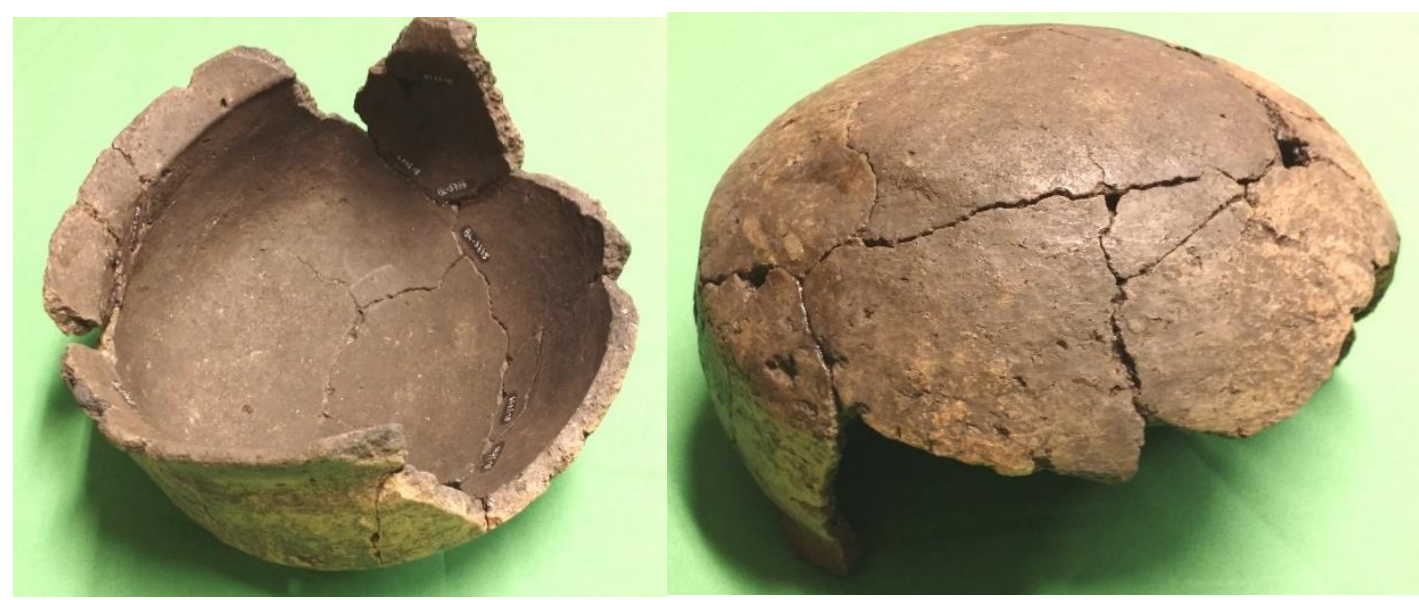

Fonte: Autor, 2016. 


\subsection{REQUISITOS}

Antes mesmo de iniciar a escolha das técnicas, foi realizado um levantamento de requisitos com a equipe de pesquisadores responsáveis pelas peças, a fim de definir quais as técnicas estão mais alinhadas com uma possível incorporação no fluxo de trabalho dos mesmos.

Em uma primeira entrevista foram coletados os pontos primordiais que qualquer meio digital onde a peça deve ser apresentada, seja para documentação ou para educação patrimonial, deve expor com clareza. A tabela a seguir as mostra em ordem de prioridade:

Tabela 3: Aspectos essenciais para peças digitalizadas.

\begin{tabular}{|cc|}
\hline Aspecto & Prioridade \\
\hline Forma & 1 \\
\hline Cor & 2 \\
\hline Material & 3 \\
\hline Tamanho & 4 \\
\hline Detalhes finos & 5 \\
\hline
\end{tabular}

Fonte: Autor, 2016.

Tendo em vista que esses pontos têm como foco a análise a partir de imagens e considerando que essa equipe já realizou testes com reconstrução 3D no passado, transpor com mais precisão esses requisitos para o que o modelo resultante deve ter foi bem direto.

É fundamental que o usuário, à primeira vista, compreenda a forma geral da peça sem distorções que influenciem na dificuldade dessa etapa. Em seguida a próxima relação estabelecida é com a cor e material do objeto que somados à forma, prontamente definem que tipo de objeto se trata. A cor tem prioridade maior, visto que é o primeiro impacto visual. Seguida do material que pode ser traduzido, em um objeto 3D, na textura. Noções de tamanho e detalhes finos são importantes principalmente para o processo de documentação já que são dados influenciadores no processo de pesquisa. Com base nisso a Tabela 1 age como uma lista complementar para a escolha das técnicas que tenham por objetivo os aspectos tratados neste item, e ao serem correlacionados, podemos chegar a uma lista de requisitos que compreendem o custo, a precisão e habilidades para operação. 
A precisão será a união de vários requisitos levantados por Pavlidis et al (2007) (Tabela 1) compreendo a captura da forma, tamanho e detalhes finos, respectivamente em ordem de prioridade. Já a habilidade para a operação se estende da rapidez em que o resultado é obtido e de quantas etapas são necessárias para encontrá-lo. Por fim, o custo é um agente mediador entre os métodos, ele vai indicar qual o melhor método para uma dada razão de captura. Por exemplo, escaneamento a laser pode se tornar inviável para uma coleção de peças muito grande devido a alocação de vários profissionais e/ou aparelhos, ou mesmo muito pequena, caso seja para captar uma única peça.

\subsection{MÉTODOS DE RECONSTRUÇÃO}

Tendo em vista os requisitos levantados no último tópico, três técnicas foram escolhidas a fim de compreender os objetivos do trabalho, estas foram a fotogrametria, profundidade (captada por um misto de laser infravermelho e luz estruturada) e laser. A rapidez e facilidade em se obter o produto é fundamental, logo a captura por laser exerce papel de controle entre os resultados.

As reconstruções por fotogrametria e profundidade foram escolhidas por apresentarem uma notável capacidade de democratizar essa área que por muitas vezes é vista como dificultosa e isolada a especialistas. Entretanto, hoje várias soluções gratuitas e portáteis estão disponíveis para a captura e reconstrução da superfície em 3D usando fotogrametria, entre eles estão o 123D Catch da Autodesk Inc. (iOS, Android, Windows Phone e Windows PC) ou o Recap 360 (Web-Based) da mesma companhia (.obj, .3dp, .stl), o Forge da About Labs, O Scann3D da SmartMobileVision, o 3D Scanner do usuário Andreyadev (Google Play), além de alguns outros que requerem algum tipo de acessório ou foram desenvolvidos como companion app, desses alguns destaques são o Mo3dls Lite da Moedls (Android e iOS), iSense da 3D Systems (iOS), o Scan3D da Pegus-Apps (Android e iOS). Todavia, a grande maioria tem seu funcionamento reduzido pelo modelo de negócio escolhido. Alguns limitam a quantidade de imagens que podem ser usadas no processamento em versões gratuitas, enquanto outros mostram modelos de resolução baixa ou com muitos artefatos, praticamente obrigando o usuário a pagar uma assinatura. 
De todos estes aplicativos, o que proveu os melhores resultados foram os da Autodesk, principalmente o 123D Catch (resultados que podem ser extendidos ao Recap 360). Com ele foi possível obter um modelo 3D já preparado para compartilhamento e disponível em três formatos diferentes: OBJ, 3DP e STL. Por outro lado, é o único dos citados que não usa o dispositivo próprio para a geração da superfície, as imagens são enviadas para a Autodesk, de onde são processadas para que o resultado seja retornado ao dispositivo como um arquivo 3D online, passível de manipulação. Desta forma, o dispositivo não mantém uma cópia local do modelo criado, apenas permanecem locais as fotos originais.

O modelo de exemplo a seguir (Figura 11), mostra como se dá uma reconstrução utilizando o 123D Catch, o aplicativo facilita o processo de captura de imagens guiando o usuário a todo momento, através de um Heads Up Display na tela assistido pelo acelerômetro e pelo giroscópio. Ele exige um mínimo de 24 imagens, e por isso a captura pode tornar um fator de dificuldade para principiantes.

Figura 11: Reconstrução pelo 123D Catch.

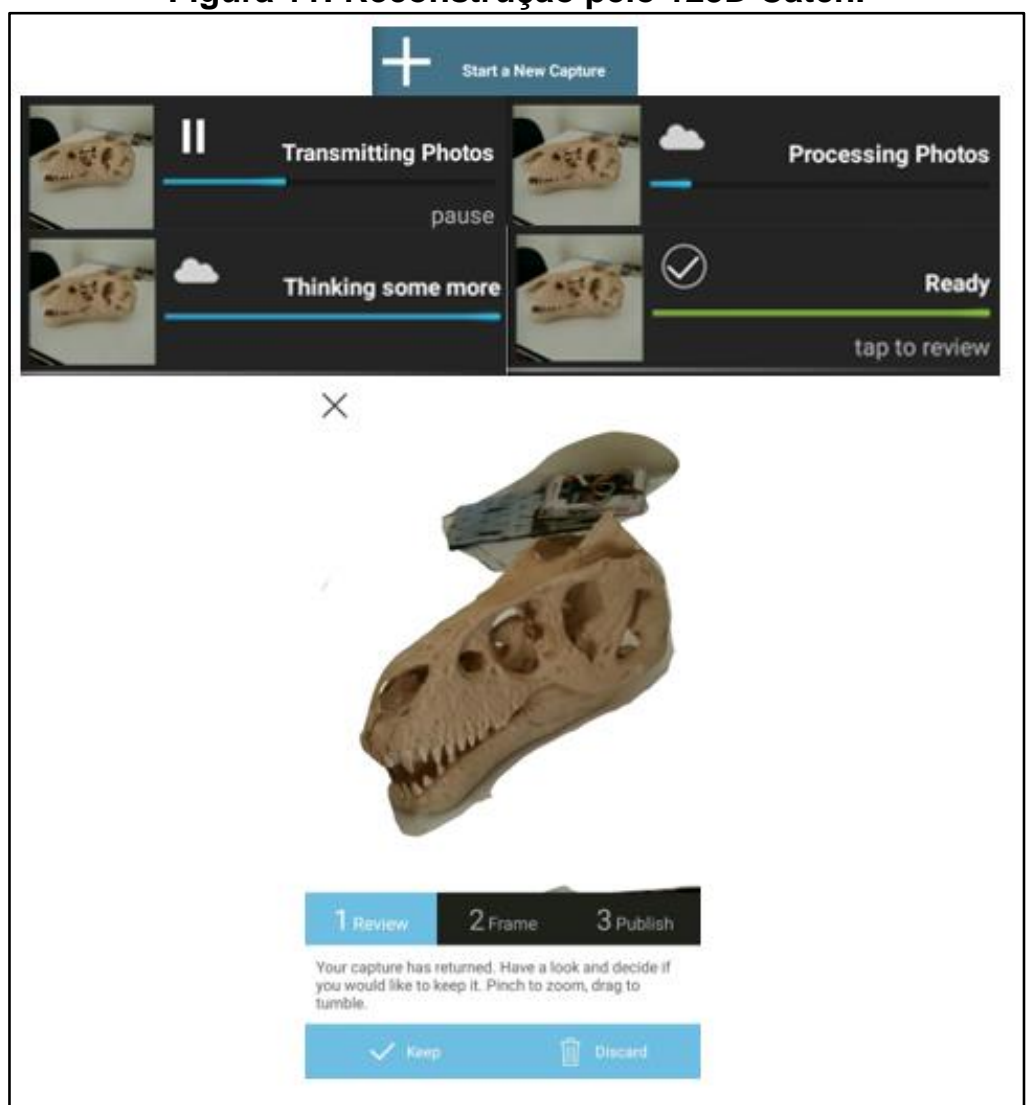

Fonte: Autor, 2016. 
O processo de captura não seguiu um rígido controle de posicionamento da peça, controle de iluminação ou mesmo controle da câmera, mostrando assim que a facilidade de gerar um modelo é alta. Por essa razão, é uma aplicação que pode encontrar na comunicação da arqueologia e paleontologia musealizada uma forte aliada. Ao utilizar essa tecnologia para demonstrar processos, também podem oferecer conteúdo científico usando os próprios dispositivos dos estudantes sob políticas de Bring Your Own Device, como mostram as perspectivas para futuro pelo Horizon Report de 2015 para a educação básica [JOHNSON et al, 2015].

O aspecto midiático e social que essa solução oferece coloca-a como uma possível escolha em iniciativas voltadas à educação. Por outro lado, provê modelos inviáveis para a proposta. Assim, esta fora descartada como a opção fotogramétrica.

\subsubsection{Laser}

Este método foi escolhido para ser incorporado no trabalho por fornecer uma densidade de point cloud alta e de maior precisão, e assim atuar como ferramenta de controle. A captura através deste método deve seguir um rígido controle. Há uma lista de modelos acessíveis e portáveis onde os de maior destaque são o Matter\&Form que oferece uma resolução de $0,43 \mathrm{~mm}$ e erro de aproximadamente 5,2mm, o MakerBot Digitizer com resolução de $2 \mathrm{~mm}$ e erro de $4,4 \mathrm{~mm}$ (porém descontinuado) e 0 NextEngine 3D, este último um scaner capaz de prover um nível alto de resolução além da portabilidade e facilidade de captura.

Sendo assim, as peças em questão foram colhidas através do NextEngine 3D Scanner modelo 2020i, que possui dois modos de captura, um Macro que compreende um espaço de $12,9 \mathrm{~cm}$ por $9,6 \mathrm{~cm}$ e densidade de pontos de até $268 \mathrm{mil}$ pontos $/ \mathrm{pol}^{2}$, e outro Wide.com alcance de $34,30 \mathrm{~cm}$ por $25,6 \mathrm{~cm}$, provendo uma densidade de até 29 mil pontos $/ \mathrm{pol}^{2}$. Para um scaner a laser ele é um pouco mais veloz, condizendo com a necessidade da área de pesquisa de patrimônio cultural. Isso se deve ao fato de ele coletar 50 mil pontos/segundo usando um par de matrizes com 4 lasers cada.

Segundo sua documentação [NEXTENGINE, 2018], ele oferece uma precisão dimensional de aproximadamente 100 mícrons no modo Macro e de 300 no modo Wide, fornecendo assim em torno de $0,1 \mathrm{~cm}$ de resolução e de erro. 
Figura 12: Scaner à laser utilizado

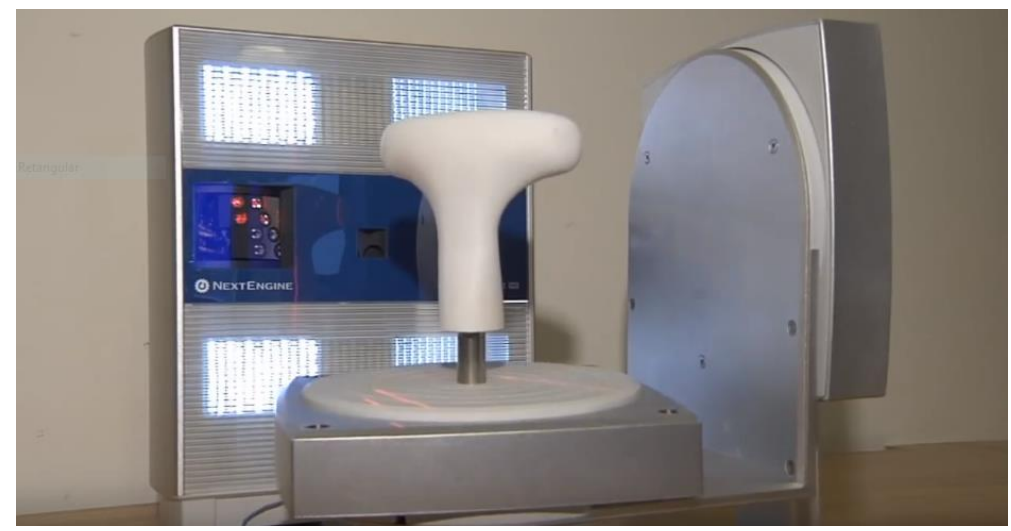

Fonte: Schreiner Productions, 2012. Link:

https://www.youtube.com/watch?v=x9F7Ai5tuNQ, acessado em <fevereiro de 2018>.

Uma vez escolhido o meio de captura, é fundamental compreender e definir um formato de arquivo 3D padrão para cada aplicação da reconstrução, visto que os objetivos divergem de uma para a outra. No caso das experiências a seguir temos três aplicações diferentes, em ordem ascendente na necessidade de maior precisão: duas na experiência de musealização (catalogação para salvaguarda com metadados e em processos educativos dentro do museu), outra sobre experiências em processos educativos para sala de aula. Logo, a escolha do formato de arquivo, se baseia no objetivo de reconstrução da peça.

Considerando todos os prós e contras de cada um dos formatos mais utilizados, foi escolhido primariamente o OBJ, visto que sua maior desvantagem para o cumprimento dos requisitos é o tamanho do arquivo gerado, porém é contornável utilizando algum modo de compressão externa. Não que alguma seja utilizada neste trabalho, visto que está diretamente relacionado ao tamanho das texturas.

\subsubsection{Montagem}

Com a finalidade de obter o melhor resultado nos processos utilizando fotos ou profundidade, foram testadas três formas para a captura dos dados. A primeira pode ser definida como montagem livre e consistiu em definir uma configuração para as câmeras (Canon Rebel 50D e Intel RealSense SR300) permitindo o movimento em torno ao objeto com as distâncias e espaços entre objetos bem definidos e utilizando um tripé para melhor estabilidade (Figura 13), na segunda a câmera permaneceu estática e uma plataforma foi utilizada para rotacionar o objeto em incrementos de $20^{\circ}$. 
$\mathrm{Na}$ terceira, uma filmadora foi utilizada de forma livre, captando até 2 min de gravação em torno do objeto. Em testes preliminares, com iluminação controlada e fundo verde, a filmadora forneceu os melhores resultados por fotogrametria e foi definida em seu lugar.

Figura 13: Setup com tripé, $h_{1}=70 \mathrm{~cm}, h_{2}=28 \mathrm{~cm}, d=60 \mathrm{~cm}$

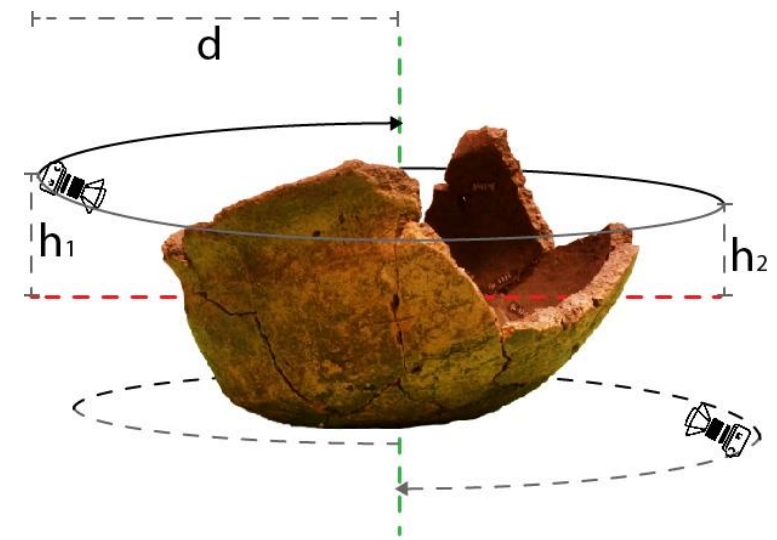

Fonte: Autor, 2018.

\subsubsection{Fotogrametria}

É o método utilizado para fazer o processo inverso da fotografia, reinserindo as informações perdidas no processo de captura em imagem bidimensional através de múltiplas amostragens, utilizando diferentes ângulos do mesmo ponto e interesse. Como o exemplo abordado no início do capítulo, a fotogrametria tem a potência de fornecer maior flexibilidade para a captura de peças.

A coleção de dados foi captada usando uma câmera que pode fornecer uma boa qualidade de imagem (3840×2160 pixels) enquanto ainda se mantém portável, a escolha foi pelo smartphone da Samsung N9005, que pode ainda manter em armazenamento uma boa quantidade de capturas (32GB de capacidade). Isso é fundamental em campo.

Cada peça foi capturada duas vezes em resolução $4 \mathrm{~K}$ em 30 quadros por segundo a uma exposição baixa e calibrada usando uma escala e um padrão xadrez, para fim de assimilar todos os lados a mesma. Nesse formato de captura, o padrão a ser seguido apenas foi o de circular a peça fazendo duas matrizes de elevação, uma superior para captar o máximo possível do topo e outra lateral. Com esses dados foi 
possível separar todos os quadros da filmagem e obter imagens bidimensionais que sobrepõem, entre si, por no mínimo 70\% com muito mais rapidez e facilidade que com a câmera fotográfica profissional no tripé.

O algoritmo, a partir de um par de imagens, identifica pontos de referência comuns a ambas. O elevado número de pontos em comum facilita bastante 0 algoritmo de extração de ponto de interesse (SIFT ${ }^{7}$ ). Consequentemente, quanto maior a quantidade de pontos encontrados, maior a quantidade de pontos em comum entre imagens que também podem ser encontrados pelo algoritmo RANSAC ${ }^{8}$. Para isso o VisualSFM foi fundamental em gerar essas correspondências entre imagens. Através disso, pontos esparsos podem ser encontrados usando Structure from Motion de imagens não previamente calibradas [AZEVEDO, TAVARES e VAZ, 2009]. E finalmente, uma point cloud densa pode ser gerada através do algoritmo Patch-based Multi-View Steropisis.

Para o resultado mostrado na figura abaixo foi captado um vídeo de 113 segundos que resultou em 3.390 quadros em alta resolução. O que permitiu a extração de 1 quadro a cada 30 quadros (1 s) reduzindo, assim, a coleção de imagens à 113 quadros, demonstrando que é uma amostragem suficiente para este objeto, além disso demonstra também a flexibilidade para uma nova amostragem, caso não tenha sido suficiente. Nas imagens a seguir os resultados ficam bem claros. Enquanto na esquerda temos uma reconstrução a partir de 113 quadros em 4K, na direita temos uma reconstrução a partir de 71 fotos tiradas com uma câmera profissional, também em 4K. Nota-se que a amostragem maior conseguiu prover resultados mais precisos.

\footnotetext{
${ }^{7}$ Lowe, David G. 2004. Distinctive image features from scale-invariant keypoints. David G. Lowe, International Journal of Computer Vision, 60, 2. pp. 91-110 ${ }^{8}$ Fischler, M.A. e Bolles, R.C. 1981. Random sample consensus: A paradigm for model fitting with applications to image analysis and automated cartography. Communications of the ACM, 24(6):381-395.
} 
Figura 14: Vaso, área interna

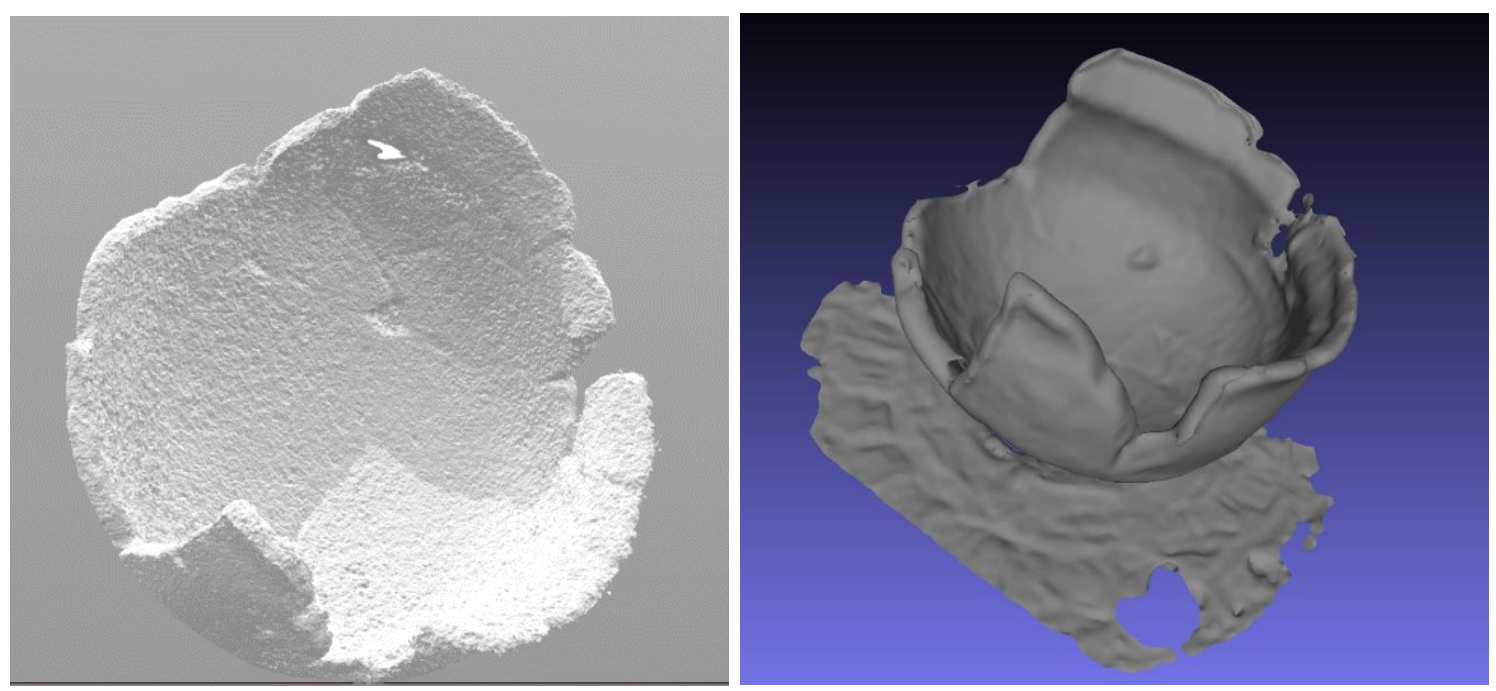

Fonte: Autor, 2017.

A quantidade de quadros escolhidos a partir da coleção de quadros capturados de cada objeto seguiu um padrão dependente da velocidade em que foi realizada a filmagem, considerando um mínimo de $80 \%$ de sobreposição em cada par de imagens, taxa esta que deve ser aumentada de acordo com aspectos específicos à cada objeto como o seu tamanho, a distância e a quantidade de detalhes que sirvam como pontos de referência para o algoritmo. Para separar estes quadros, foi usado o software VirtualDub (2013) [SISMANOGLU et al, 2009]. Por meio da tabela a seguir, é possível identificar que a amostragem deve ser maior principalmente caso o objeto esteja distante da câmera (nesse caso, a ponta de flecha, sendo um pequeno objeto e com superfície uniformemente irregular, apresentou a necessidade de uma coleta de quadros maior que de todos os outros).

Tabela 4: Número de quadros por coleção

\begin{tabular}{|c|c|c|c|c|}
\hline Objeto & Área & $\begin{array}{l}\text { Total de } \\
\text { quadros } \\
\text { escolhidos }\end{array}$ & $\begin{array}{c}\text { Média } \\
\text { APROXIMADA } \\
\text { de DECIMAÇÃO } \\
\text { DE quadros }\end{array}$ & $\begin{array}{l}\text { Total de } \\
\text { quadros }\end{array}$ \\
\hline \multirow{2}{*}{ Ponta de Flecha } & Topo & 463 & 5 & 2337 \\
\hline & Base & 446 & 5 & 2233 \\
\hline \multirow{2}{*}{ Machadinha } & Topo & 126 & 15 & 2059 \\
\hline & Base & 319 & 5 & 1595 \\
\hline \multirow{2}{*}{ Borda de Vaso } & Topo & 472 & 5 & 2362 \\
\hline & Base & 85 & 30 & 2561 \\
\hline
\end{tabular}




\section{Vaso}

\section{Topo}

Base

\section{3}

159
30

15
3407

2151

Fonte: Autor, 2017.

\subsubsection{Profundidade e luz estruturada}

Várias tecnologias com câmera ou sensores esteroscópicos foram cogitadas para esta etapa, dentre elas se destacaram o Kinect da Microsoft, o qual já possui extensa literatura voltada para reconstrução e o RealSense da Intel, onde apesar bem mais recente é disponibilizado voltado principalmente para o uso em reconstrução e reconhecimento de imagem.

Logo, foi escolhida a RealSense ${ }^{T M}$ SR300 da Intel ${ }^{\circledR}$ (Figura 15), pela sua portabilidade e por possuir duas câmeras, sendo uma de infravermelho e uma RGB, e um laser infravermelho. Ela capta o fluxo de vídeo de profundidade usando o laser infravermelho para gerar uma série de padrões codificados que serão deformados pela cena, tal qual o método por luz estruturada [INTEL, 2016, p.14]. Ela pode fornecer captura em tempo real.

Figura 15: Sistema do modelo SR300

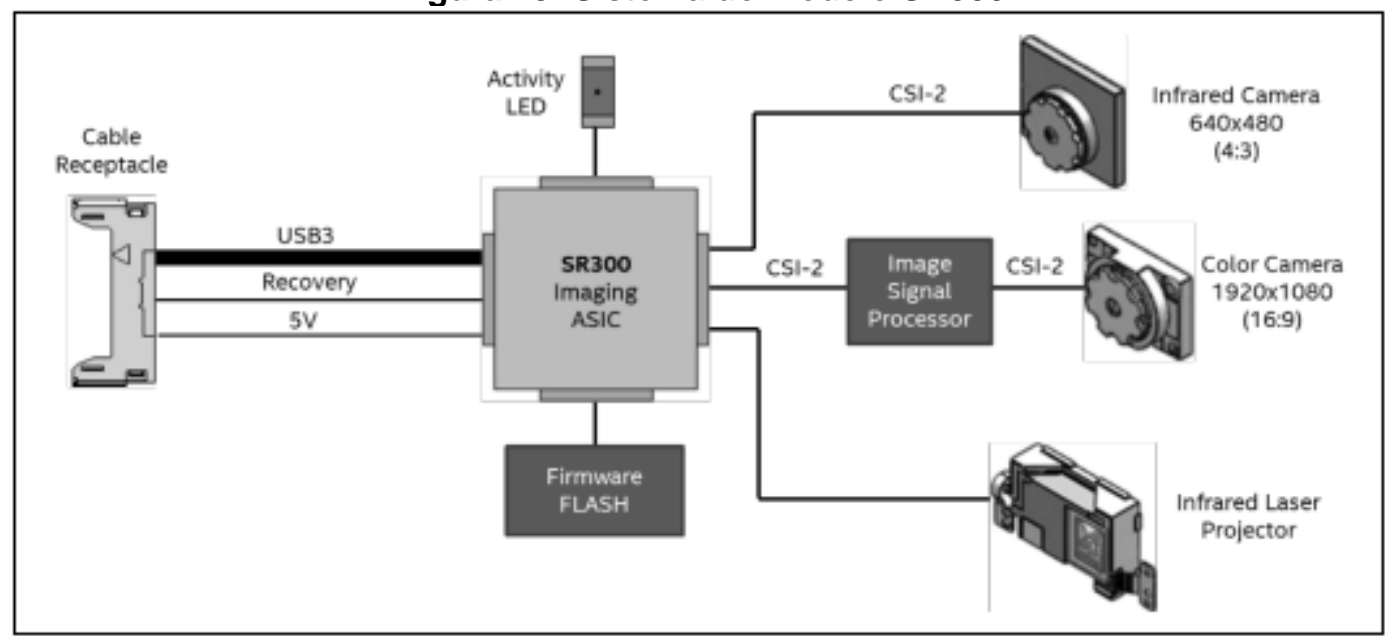

Fonte: INTEL, 2016, p. 13.

Esse modelo da câmera usa USB 3.0 e já conta com SDK para Windows e prevê melhor usabilidade quando associado a um processador também Intel, todavia funciona normalmente em processadores AMD. Após testes, foi detectado que nestes processadores, a resolução da câmera RGB fica limitada ao máximo que a resolução do par de câmeras infravermelhas atinge. O modelo SR300 é voltado para a 
reconstrução em tempo real de objetos com até $50 \mathrm{~cm}$ e por isso possui um occlusion culling para elementos muito distantes, por outro lado o modelo R200 cumpre com requisitos para a reconstrução de objetos muito distantes (até $2 \mathrm{~m}$ ). Vários computadores pessoais já estão no mercado com esses modelos embutidos, algo que claramente pode configurar uma facilitação na obtenção de peças em arquivos 3D.

Uma avaliação quantitativa para o uso dessa tecnologia buscou primariamente compreender os requisitos levantados no anteriormente (Tabela 3) e abranger os métodos que devem ser empregados para o melhor resultado, dado o contexto do usuário. Assim, a primeira etapa consistiu em definir como a tecnologia pode ser aplicada, dado o tempo reduzido que pode ser destinado pelo arqueólogo a este fim, principalmente em sítios com quantidade muito grande de objetos. Para isso as capturas foram realizadas usando a montagem livre (p. 46) com a câmera em movimento, e com outra com a câmera estática e o objeto em uma plataforma rotatória. Em ambos os casos foram usados notebooks, tendo em vista que tanto os modelos avulsos da SR300 quantos os da R200 não possuem até esta data o SDK para Android, assim foram utilizadas conectadas a um notebook rodando o sistema operacional Windows 7.

Em testes preliminares de captura, a câmera se mostrou altamente dependente de uma CPU de alto desempenho, esse fator influencia de forma massiva e direta a velocidade e precisão na aquisição dos pontos. Isso acontece porque a CPU precisa suprir com a necessidade processar uma quantidade e quadros ao mesmo tempo, caso contrário a quantidade de pontos gerados tornaria a prática inutilizável em tempo real, então como os pontos não são captados e sim gerados através de um algoritmo de voxelização. Entretanto, apesar de existir a possibilidade de agregar uma GPU e assim fornecer um aumento considerável na precisão, a variedade de modelos a disposição em campo é reduzida. Em linhas gerais, a reconstrução pode ser realizada, porém o tempo de captura, a estabilidade da câmera e o movimento em torno do objeto são devem variar de acordo com a CPU/GPU escolhida.

Em ambas as montagens, cada peça foi registrada duas vezes, sendo uma para captar a parte superior e outra para a inferior, bem como na captação fotogramétrica, porém durante a captação usando a montagem livre o registro pode ficar inconsistente (Figura 16) devido a elementos humanos, como tremer a câmera, rotacioná-la involuntariamente, movimentos bruscos em contraste com lentos, etc. 


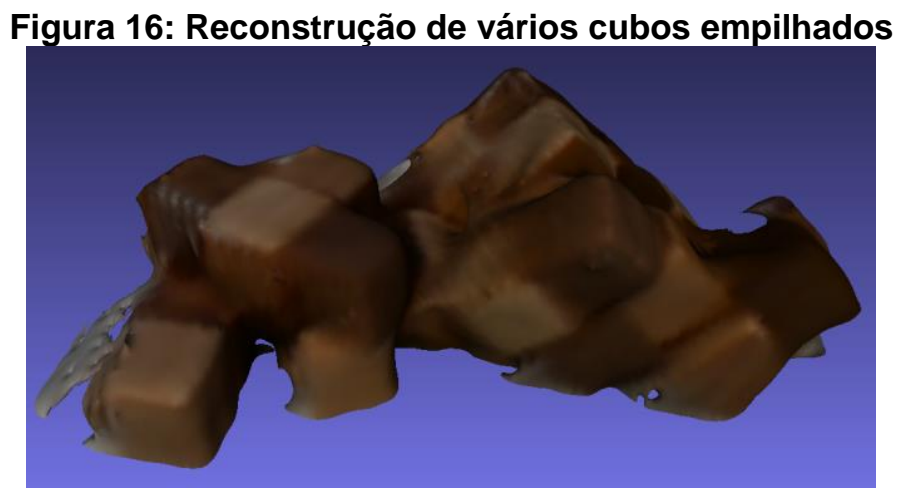

Fonte: Autor, 2016

Dessa forma, a maior parte das capturas retornaram coleções de pontos que retratam objetos grossamente simplificados ou apenas formas completamente diferentes, no caso da ponta de flecha os pontos obtidos indicaram nada mais que uma protuberância em meio a um plano, não condizendo assim com o objeto em analise, como mostra a imagem abaixo:

Figura 17: Modelos capturados em movimento

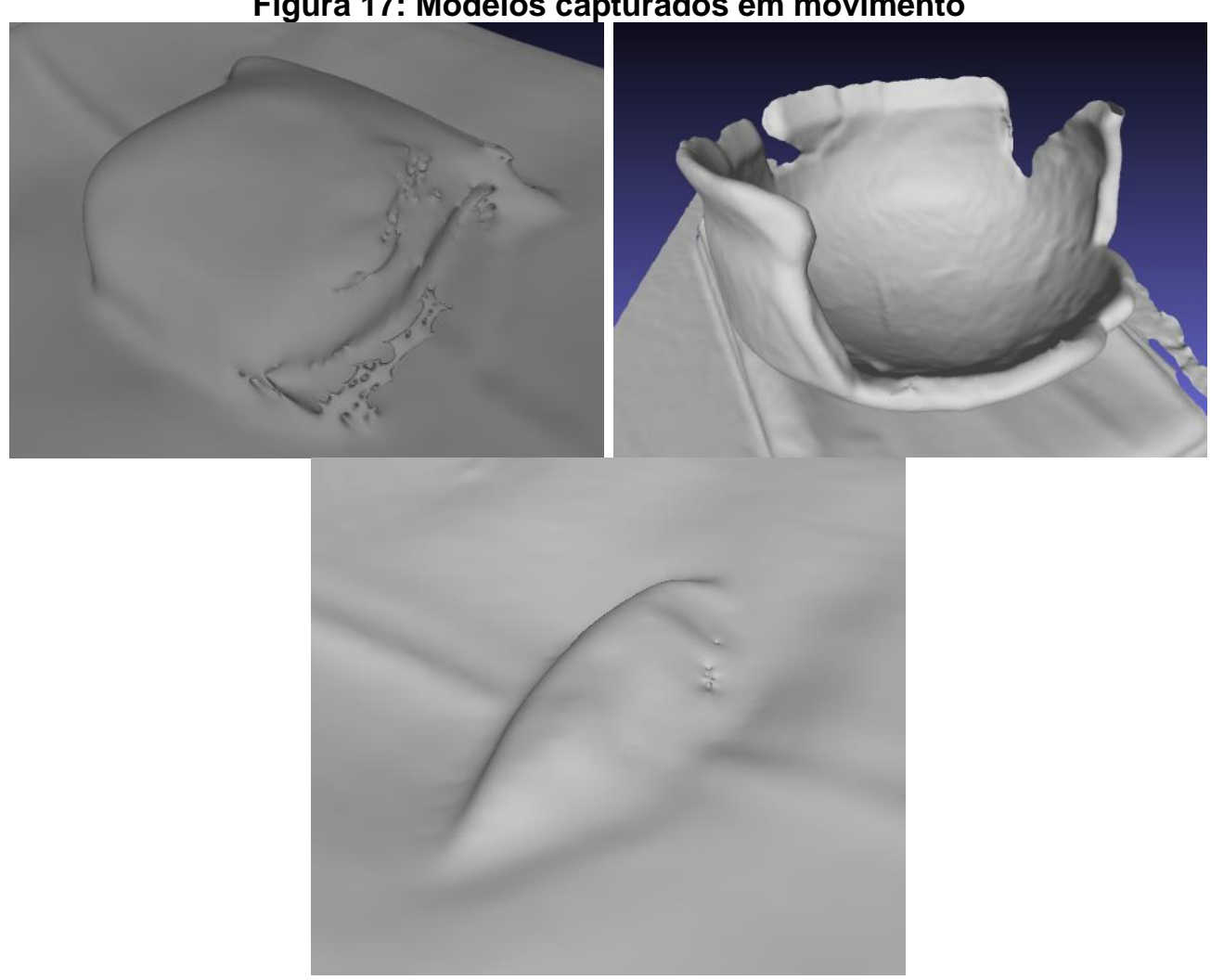

Fonte: Autor, 2016 
Por outro lado, a montagem com a câmera estática proveu resultados mais próximos da forma geral. Montada ao topo da tela do notebook, a fim de aproximar de um contexto de campo, ficou completamente estática enquanto que ao modelo amparado por uma plataforma rotatória foi adicionado um incremento constante e linear de $20^{\circ}$ por 4 segundos, onde considerando a capacidade da configuração (computador e cabos) foi a velocidade ótima para a captura sem deformação da forma geral do objeto, levando então a ser adotada como máxima. Essa velocidade permitiu a captura por períodos prolongados para fim de encontrar novos pontos e detalhes no fluxo de vídeo de profundidade, a tabela a seguir expõe o tempo de captura para cada peça:

Tabela 5: Tempo de captura para cada peça

\begin{tabular}{|c|c|c|c|}
\hline OBJETO & ÁREA & $\begin{array}{l}\text { TEMPO (EM } \\
\text { SEGUNDOS) }\end{array}$ & $\begin{array}{l}\text { QUANTIDADE } \\
\text { DE VERTICES }\end{array}$ \\
\hline \multirow{2}{*}{ Ponta de Flecha } & Topo & 96 & 11.685 \\
\hline & Base & 138 & 16.613 \\
\hline \multirow{2}{*}{ Machadinha } & Topo & 319 & 25.486 \\
\hline & Base & 435 & 40.910 \\
\hline \multirow{2}{*}{ Borda de Vaso } & Topo & 305 & 46.125 \\
\hline & Base & 216 & 30.607 \\
\hline \multirow{2}{*}{ Vaso } & Topo & 489 & 263.400 \\
\hline & Base & - & - \\
\hline
\end{tabular}

Fonte: Autor, 2016

De acordo com esses dados podemos perceber que no caso do vaso há uma disparidade bem grande na malha gerada, isso é reflexo da aliança de três características dele, o tamanho, a forma e os detalhes. Os detalhes atuam como registradores e mantém os algoritmos de pairmatching (encontrar os pontos de interesse e correlaciona-los) em sincronia com o objeto, levando ao tamanho que permite uma quantidade de detalhes maior, e logo mais pontos. A forma define como diferentes o topo e a base, evitando assim que detalhes similares próximos ao limite do objeto estejam passíveis de serem detectados errado, por isso ela favorece a abordagem livre, onde a chance de perder pontos de referência é reduzida. Mesmo Assim, esta deve ser priorizada em ambientes menos controlados com em sítios ou em situações em que o tempo é crucial, enquanto que comparativamente com a 
captura em movimento livre o resultado é uma malha inferior em termos de precisão, porém garante que o mínimo de falhas aconteçam durante o processo, visto que ela é construída em tempo real e qualquer perda no registro dos pontos pode destruir o modelo. É cumprido assim com um dos principais requisitos, porém leva a outro não menos importante, a habilidade para operação.

Figura 18: Modelos reconstruídos em tempo real

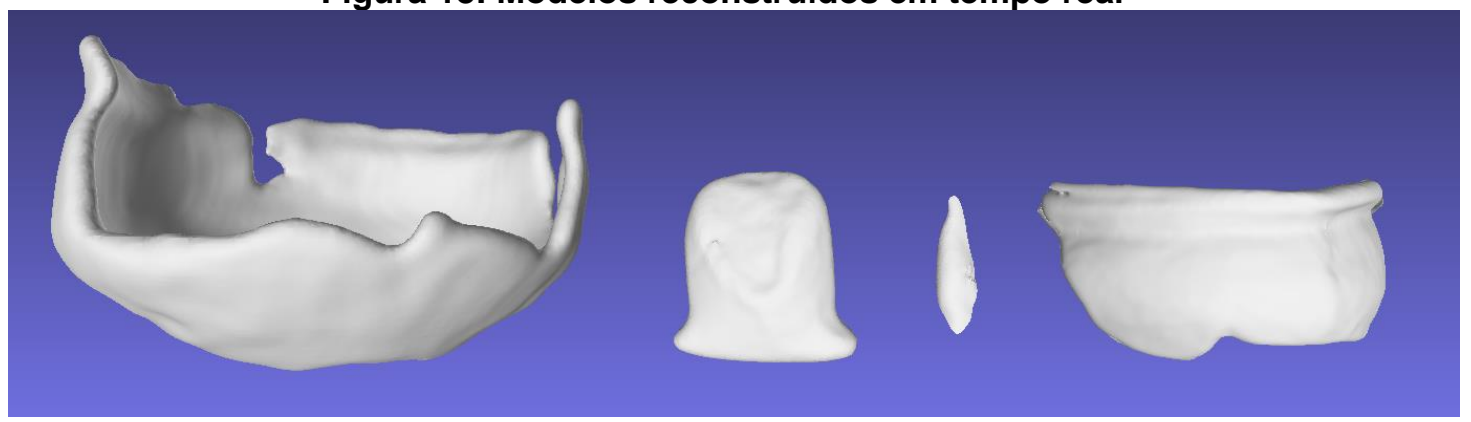

Fonte: Autor, 2016

O usuário deve passar por algum treinamento para fim de estar hábil a capturar malha usando esta tecnologia, ela está alinhada com a proposta em termos de facilidade já que cada um dos objetos na imagem acima foi capturado em tempo real. Seguindo todo o descrito para a obtenção de uma peça virtualizada não é o suficiente, ela deve ser limpada de pontos ou faces excedentes, alinhada à sua contraparte caso tenha para que então essas partes sejam unidas.

Ao fazer a captura, o usuário deve importar as duas partes do objeto ao programa de edição de 3D de preferência, podendo ser Blender, MeshLab, 3Ds Max®, Maya®, ZBrush®, MudBox® ou afins, uma vez importados o usuário deve alinhar as duas partes e juntá-las, em alguns casos até reconstruir manualmente caso apresente alguma falha, por essa razão o ZBrush®, o Mudbox® e o MeshLab são mais viáveis por tratarem malhas muito grandes com maior facilidade, entretanto os dois primeiros necessitam de uma curva de aprendizado bastante íngreme e seu algoritmos não são transparentes visam um resultado artístico, o que dificulta a replicação.

O MeshLab [CIGNONI et al, 2008] é uma opção ideal por fornecer uma plataforma aberta e gratuita onde os algoritmos, lá chamados de filtros, podem ser adicionados e alterados caso seja necessário. Nele todas as partes da peça deve ser importada e alinhada através da opção de alinhamento presente na barra de tarefas 
ou no menu de filtros, de lá uma das malhas escolhidas deve ser colada para assim manter a sua posição fixa, então são alinhadas através do método de colagem baseado em pontos, onde vários pontos correlatos são escolhidos em ambas as malhas e com base nesses pontos uma matriz de transformação é aplicada ao objeto livre. Caso o objeto tenha algum buraco o processo de alinhamento não fechou a malha, é preciso rodar o algoritmo de reconstrução de superfície de Poisson com uma profundidade de árvore octária de 12, assim o MeshLab [KAZHDAN e HOPPE, 2013] gera uma nova o mais próximo possível da malha original com áreas reconstruídas para eliminar esses eventuais buracos.

O processo de pós-produção da malha requer um breve treinamento para o profissional, porém possui uma curva de aprendizado bastante baixa, desde a limpeza até a reconstrução de áreas não captadas pode levar alguns minutos, permitindo assim que em caso de dificuldades em alinhamento ou falta de áreas inteiras, mais dados sobre o objeto pode podem ser captados. Logo, maior a habilidade sobre as etapas, maior a flexibilidade e rapidez do processo, agregando assim à rastreabilidade do método.

\subsection{AVALIAÇÃO QUANTITATIVA}

Aplicando o modelo de métricas de qualidade previsto no tópico de reconstrução musealizada (Item 3.6) aos passos realizados durante os processos por fotogrametria e por profundidade, temos a precisão, a rastreabilidade e a compatibilidade e suas respectivas relações para com os requisitos levantados.

\subsubsection{Precisão}

Por ser definida através da diferença volumétrica entre os artefatos digitalizados e cada contraparte escaneada à laser, pode ser encontrada após todo o processo de digitalização, que como abordado anteriormente compreende a captura, reconstrução e ajustes da malha.

Uma vez os objetos finalizados, suas malhas e os point clouds de suas respectivas contrapartes de controle foram importadas para o software CloudCompare [EDF, 2018]. Através dele é possível utilizar uma versão similar ao algoritmo desenvolvido pode Cignoni et al (1998) para calcular diferenças entre malhas usando 
a distância de Hausdorff, só que para isso é preciso que ambos os objetos de comparação sejam point clouds, visto que apesar haver uma opção de comparação entre malha e point cloud, o processo cria uma amostragem de point cloud usando a malha original para então compará-la, por essa razão o ponto da malha é subamostrado usando um algoritmo com base em árvore octária, onde o ponto é alocado ao centro de cada célula da árvore, ao point cloud então é dado um limite de pontos igual ao número de pontos que constituem o modelo de controle durante este método.

Uma vez concluído este processo, é dada continuidade ao alinhamento ou registro dos artefatos para fim de alinhá-los. Isso consiste na escolha de ao menos 4 pontos para que através do algoritmo de conjunto de 4 pontos congruentes [AIGER et al, 2008] é possível aplicar uma matriz de transformação ao artefato em análise para aproximá-lo às transformações (translação, rotação e escala) do artefato de controle (Figura 19.a) [ALONSO et al, 2011]. Esse resultado é então tratado usando o algoritmo de ponto iterativo mais próximo (Iterative Closest Point - ICP) [BESL et al, 1992] para então resultar em um registro fino da malha a ser comparada (Figura 19.b).

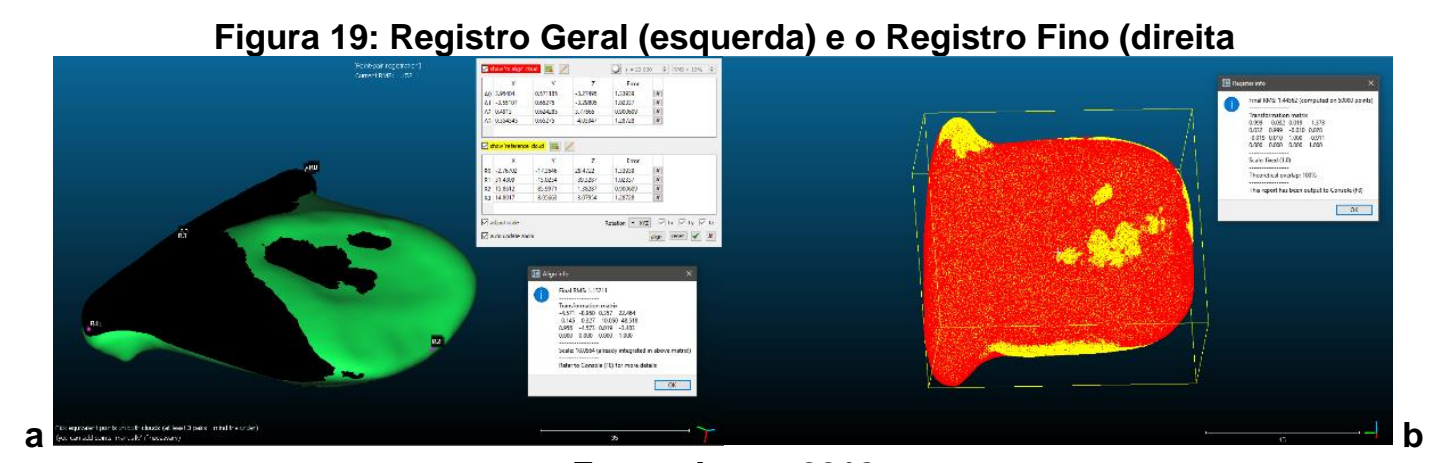

Fonte: Autor, 2018

Os objetos propriamente alinhados entre si, são então testados por sua diferença volumétrica, assumida como a distância dos pontos amostrados a partir das malhas captadas, aos pontos de controle [NEAMTU et al, 2014]. A partir dos resultados obtidos através do uso do algoritmo descrito por Cignoni et al [1998] temos dois aspectos de relevância alta para a avaliação, estes são a distância máxima considerando o ponto mais distante e a quantidade de pontos por distância. Isso permite que seja criado um campo escalar colorido que guia a adição de informação de cor à pontos e/ou vértices, ele então pode ser usado para a plotagem de textura a 
partir das cores dos vértices contidos nesse campo, resultando assim em uma análise de desvio visualizada a partir de um mapa de desvio das diferenças entre os pontos de ambos os artefatos.

Os mapas de desvio dos erros obtidos quando os modelos capturados com o método de laser (com erro de $0,1 \mathrm{~mm}$ até $0,3 \mathrm{~mm}$ ) são comparados com os obtidos através do escaneamento em tempo real oferecido pela câmera de profundidade e com o método fotogramétrico, fornecem um retorno visual imediato do nível de precisão resultante de cada método (Figura 21 e Figura 22).

Estes mapas traduzem visualmente o ponto mais distante (vermelho) ao ponto mais próximo (azul), com base nas dimensões dos objetos em milímetros. Logo, por serem muitos pontos em análise, oito clusters (Figura 20) que referenciam as coleções de distâncias foram adotados e marcados com cores. Na tabela a seguir temos a relação de objetos por distância máxima de pontos [ALONSO et al, 2011].

Figura 20: Código de cor para cada cluster

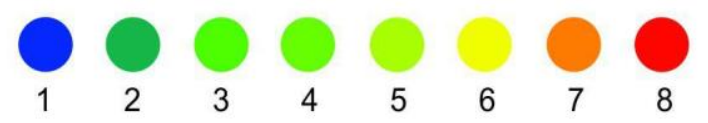

Fonte: Autor, 2017.

Concluído todo o processo temos como resultados uma coleção de dados que podem ser tratados para melhor visualizar o nível de erro contido em cada um dos métodos.

\subsubsection{Vídeo}

Os conjuntos de dados obtidos a partir dos resultados estão como segue:

Tabela 6: Relação de pontos nos artefatos resultados de fotogrametria

\begin{tabular}{cccc}
\hline OBJETO & TAMANHO $(\mathrm{mm})$ & $\begin{array}{c}\text { QUANTIDADE DE } \\
\text { PONTOS }\end{array}$ & $\begin{array}{c}\text { PONTOS MAIS } \\
\text { DISTANTES }(\mathrm{mm})\end{array}$ \\
\hline Ponta de Flecha & $\begin{array}{c}15,62 \times 71,47 \times \\
23,14\end{array}$ & 1.500 .025 & 2,40 \\
\hline
\end{tabular}




\begin{tabular}{rccc}
\hline Machadinha & $\begin{array}{c}40,36 \times 80,04 \times \\
71,66\end{array}$ & 1.000 .204 & 3,87 \\
Borda de Vaso & $\begin{array}{c}147,75 \times 80,17 \times \\
63,68\end{array}$ & 1.499 .225 & 5,57 \\
Vaso & $\begin{array}{c}197,16 \times 176,83 \times \\
156,65\end{array}$ & 2.000 .139 & 8,72 \\
\hline
\end{tabular}

Fonte: Autor, 2017.

Tabela 7: Mapeamento dos clusters no método fotogramétrico

\begin{tabular}{|c|c|c|c|c|}
\hline \multirow{9}{*}{$\begin{array}{l}\text { PONTA DE } \\
\text { FLECHA }\end{array}$} & \multirow{2}{*}{$\begin{array}{r}\text { CLUSTER } \\
1\end{array}$} & \multirow{2}{*}{$\begin{array}{l}\text { QUANTIDADE } \\
\text { DE PONTOS } \\
641589\end{array}$} & \multicolumn{2}{|c|}{$\begin{array}{c}\text { ALCANCE DOS GRUPOS DE } \\
\text { DISTÂNCIAS }\end{array}$} \\
\hline & & & 0,0003848 & 0,3009106 \\
\hline & 2 & 421513 & 0,3009106 & 0,6014364 \\
\hline & 3 & 220857 & 0,6014364 & 0,9019622 \\
\hline & 4 & 114429 & 0,9019622 & 1,2024879 \\
\hline & 5 & 51229 & 1,2024879 & 1,5030137 \\
\hline & 6 & 29526 & 1,5030137 & 1,8035395 \\
\hline & 7 & 16476 & 1,8035395 & 2,1040653 \\
\hline & 8 & 4406 & 2,1040653 & 2,4045911 \\
\hline \multirow{8}{*}{ MACHADINHA } & 1 & 487573 & 0,0030836 & 0,4871773 \\
\hline & 2 & 390487 & 0,4871773 & 0,9712711 \\
\hline & 3 & 87135 & 0,9712711 & 1,4553648 \\
\hline & 4 & 24629 & 1,4553648 & 1,9394585 \\
\hline & 5 & 4429 & 1,9394585 & 2,4235523 \\
\hline & 6 & 2713 & 2,4235523 & 2,9076460 \\
\hline & 7 & 2390 & 2,9076460 & 3,3917398 \\
\hline & 8 & 848 & 3,3917398 & 3,8758335 \\
\hline \multirow{8}{*}{$\begin{array}{r}\text { BORDA DE } \\
\text { VASO }\end{array}$} & 1 & 898991 & 0,0018456 & 0,6989132 \\
\hline & 2 & 398420 & 0,6989132 & 1,3959809 \\
\hline & 3 & 116544 & 1,3959809 & 2,0930485 \\
\hline & 4 & 40509 & 2,0930485 & 2,7901162 \\
\hline & 5 & 23030 & 2,7901162 & 3,4871838 \\
\hline & 6 & 13719 & 3,4871838 & 4,1842515 \\
\hline & 7 & 5997 & 4,1842515 & 4,8813191 \\
\hline & 8 & 2015 & 4,8813191 & 5,5783868 \\
\hline \multirow{7}{*}{ VASO } & 1 & 1537118 & 0,0026656 & 1,0927353 \\
\hline & 2 & 387340 & 1,0927353 & 2,1828049 \\
\hline & 3 & 44514 & 2,1828049 & 3,2728746 \\
\hline & 4 & 19560 & 3,2728746 & 4,3629442 \\
\hline & 5 & 8409 & 4,3629442 & 5,4530138 \\
\hline & 6 & 2488 & 5,4530138 & 6,5430835 \\
\hline & 7 & 481 & 6,5430835 & 7,6331531 \\
\hline
\end{tabular}


229

7,6331531

8,7232227

Fonte: Autor, 2017.

Assim como discutido anteriormente, os mapas de desvio para as secções de topo e base puderam ser gerados:

Figura 21: Mapa de desvio dos objetos capturados com a câmera

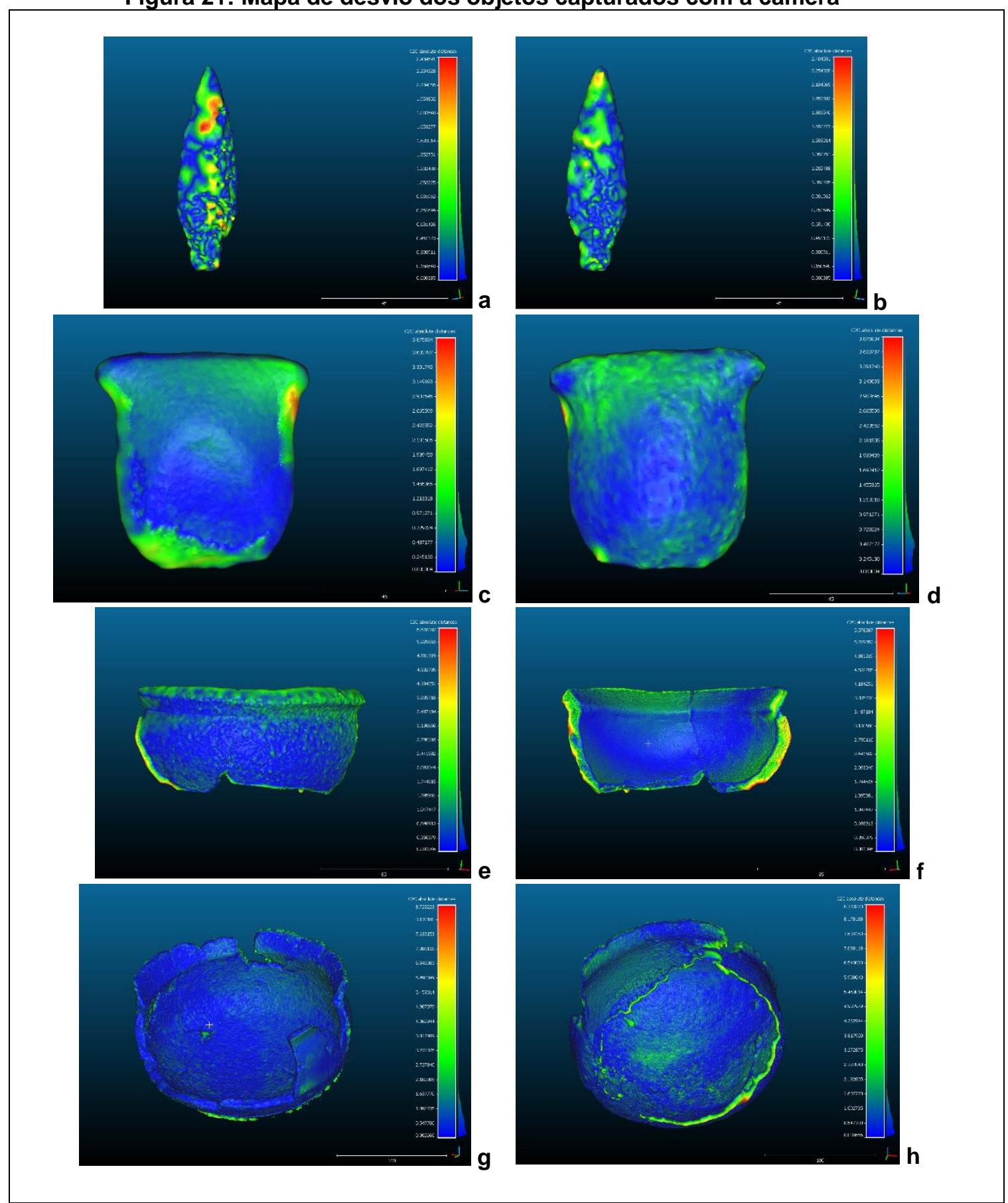

Fonte: Autor, 2017. 
Observa-se que este método pôde captar detalhes mais finos, porém permitiu danos em áreas de maior oclusão ambiental principalmente quando coincidem com as junções entre o topo e a base, onde grande parte das informações foram perdidas e tiveram que ser reconstruídas pelo algoritmo de Poisson já descrito.

\subsubsection{2 $\underline{\mathrm{SR} 300}$}

Os conjuntos de dados obtidos a partir dos resultados estão como segue:

Tabela 8: Relação de pontos nos artefatos resultados pela SR300

\begin{tabular}{|c|c|c|c|}
\hline OBJETO & TAMANHO (mm) & $\begin{array}{l}\text { QUANTIDADE DE } \\
\text { PONTOS }\end{array}$ & $\begin{array}{l}\text { PONTOS MAIS } \\
\text { DISTANTES }(\mathrm{mm})\end{array}$ \\
\hline Ponta de Flecha & $12,70 \times 72,18 \times 22,69$ & 500.059 & 3,19 \\
\hline Machadinha & $41,45 \times 79,95 \times 70,66$ & 1.000 .090 & 10,73 \\
\hline Borda de Vaso & $144,6 \times 78,93 \times 61,07$ & 999.980 & 4,47 \\
\hline Vaso & $\begin{array}{c}198,29 \times 171,2 \times \\
153,67\end{array}$ & 1.500 .108 & 6,61 \\
\hline
\end{tabular}

Fonte: Autor, 2017.

Tabela 9: Mapeamento dos clusters nos resultados pela SR300

\begin{tabular}{|c|c|c|c|c|}
\hline \multirow{9}{*}{$\begin{array}{l}\text { PONTA DE } \\
\text { FLECHA }\end{array}$} & \multirow{2}{*}{$\begin{array}{r}\text { CLUSTER } \\
1\end{array}$} & \multirow{2}{*}{$\begin{array}{l}\text { QUANTIDADE } \\
\text { DE PONTOS } \\
220722\end{array}$} & \multicolumn{2}{|c|}{$\begin{array}{c}\text { ALCANCE DOS GRUPOS DE } \\
\text { DISTÂNCIAS }\end{array}$} \\
\hline & & & 0,0016133 & 0,4006269 \\
\hline & 2 & 140089 & 0,4006269 & 0,7996404 \\
\hline & 3 & 66190 & 0,7996404 & 1,1986540 \\
\hline & 4 & 34262 & 1,1986540 & 1,5976675 \\
\hline & 5 & 20659 & 1,5976675 & 1,9966811 \\
\hline & 6 & 10638 & 1,9966811 & 2,3956947 \\
\hline & 7 & 5958 & 2,3956947 & 2,7947082 \\
\hline & 8 & 1541 & 2,7947082 & 3,1937218 \\
\hline & 1 & 910832 & 0,0019500 & 1,3429955 \\
\hline & 2 & 62027 & 1,3429955 & 2,6840411 \\
\hline & 3 & 1414 & 2,6840411 & 4,0250866 \\
\hline MACHADINHA & 4 & 4618 & 4,0250866 & 5,3661321 \\
\hline & 5 & 3918 & 5,3661321 & 6,7071777 \\
\hline & 6 & 7731 & 6,7071777 & 8,0482232 \\
\hline & 7 & 6790 & 8,0482232 & 9,3892687 \\
\hline & 8 & 2760 & 9,3892687 & 10,7303143 \\
\hline
\end{tabular}




\begin{tabular}{|c|c|c|c|c|}
\hline \multirow{8}{*}{$\begin{array}{r}\text { BORDA DE } \\
\text { VASO }\end{array}$} & 1 & 383005 & 0,0035674 & 0,5629452 \\
\hline & 2 & 322197 & 0,5629452 & 1,1223229 \\
\hline & 3 & 187965 & 1,1223229 & 1,6817007 \\
\hline & 4 & 66553 & 1,6817007 & 2,2410785 \\
\hline & 5 & 29936 & 2,2410785 & 2,8004562 \\
\hline & 6 & 8899 & 2,8004562 & 3,3598340 \\
\hline & 7 & 1139 & 3,3598340 & 3,9192118 \\
\hline & 8 & 286 & 3,9192118 & 4,4785895 \\
\hline \multirow{8}{*}{ VASO } & 1 & 783380 & 0,0024520 & 0,8283920 \\
\hline & 2 & 460805 & 0,8283920 & 1,6543320 \\
\hline & 3 & 220704 & 1,6543320 & 2,4802720 \\
\hline & 4 & 24828 & 2,4802720 & 3,3062120 \\
\hline & 5 & 7156 & 3,3062120 & 4,1321520 \\
\hline & 6 & 1934 & 4,1321520 & 4,9580920 \\
\hline & 7 & 1063 & 4,9580920 & 5,7840320 \\
\hline & 8 & 238 & 5,7840320 & 6,6099720 \\
\hline
\end{tabular}

Fonte: Autor, 2017. 
Figura 22: Mapa de desvio dos objetos capturados com a RealSense SR300
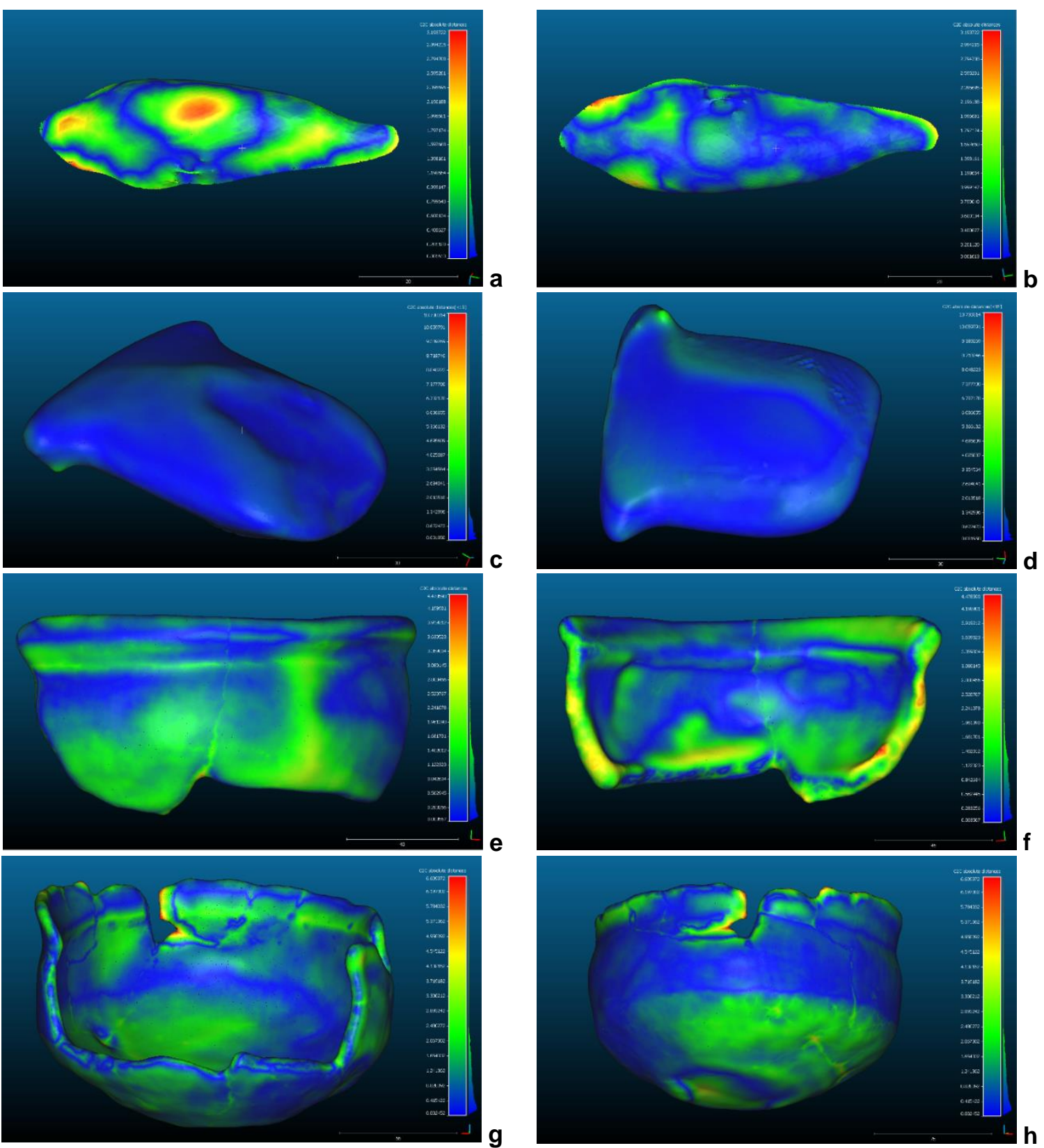

Fonte: Autor, 2017.

A partir destes dados podemos relacionar os dois resultados entre si, usando como fator em comum suas semelhanças ao controle e para isso o primeiro cluster foi adotado como faixa aceitável de até $12,5 \%$ de erro em relação ao ponto mais distante o que remete aos pontos que se encaixam no cluster 1 . 
Tabela 10: Relação os dois métodos

\begin{tabular}{rcccccc}
\hline \multirow{2}{*}{ OBJETO } & \multicolumn{2}{c}{ TOTAL DE PONTOS } & \multicolumn{2}{c}{$\begin{array}{c}\text { PONTOS NO } \\
\text { CLUSTER 1 }\end{array}$} & \multicolumn{2}{c}{ ERRO (\%) } \\
\hline & VIDEO & SR300 & VIDEO & SR300 & VIDEO & SR300 \\
\hline $\begin{array}{r}\text { Ponta de } \\
\text { Flecha }\end{array}$ & 1.500 .025 & 500.059 & 641589 & 220722 & 57,23 & 55,86 \\
\hline Machadinha & 1.000 .204 & 1.000 .090 & 487573 & 910832 & 51,25 & 8,92 \\
Borda de Vaso & 1.499 .225 & 999.980 & 898991 & 383005 & 40,04 & 61,70 \\
Vaso & 2.000 .139 & 1.500 .108 & 1537118 & 783380 & 23,15 & 47,78 \\
\hline
\end{tabular}

Fonte: Autor, 2017.

\subsubsection{Rastreabilidade e Compatibilidade}

Os dados fornecidos mostram como os resultados podem ser contrastantes, enquanto por um lado o vídeo forneceu modelos com detalhes mais finos, o SR300 por sua vez prioriza a forma geral (pois capta sequência de quadros de profundidade em $640 \times 480$ pixels). Isso indica diferentes usos para contextos específicos, por exemplo, vemos que a machadinha tem um erro pequeno quando captada pela câmera de profundidade, isso acontece porque sua morfologia favorece o uso de profundidade por não conter declives intensos e não requerer que seja compreendida com base em seus detalhes finos. Ambos os métodos oferecem flexibilidade dependendo do nível de habilidade dos usuários performando a captação, favorece principalmente iniciantes na reconstrução 3D.

Para manter a consistência entre os modelos, a documentação (Arquivamento) de todo o processo sempre deve ser realizada minuciosamente para que sejam analisados e escolhidos para a materialização, onde os artefatos que foram submetidos a essa triagem possam ser disponibilizados por meio físico ou digital. [SHOTT, 2014]. Para isso o formato OBJ é a melhor solução para disponibilizar para ambos os meios, visto que oferece uma grande flexibilidade entre a adição de texturas, múltiplas malhas e código aberto. Um outro formato que se encaixa ainda melhor seria o FBX, que conta com tudo que o OBJ oferece além de múltiplas animações, múltiplas câmeras, múltiplos materiais, dados de conversão de escala e tamanho reduzido, porém é propriedade fechada da Autodesk e para seu uso requer a liberação de todos os dados de usuários que utilizarem o formato. 


\section{CONCLUSÃO}

Com finalidade de documentar objetos em ambientes de pouco controle, foi proposta uma metodologia que contempla facilidade e portabilidade para o processo de escaneamento 3D. Para isso foram inicialmente identificadas as áreas de análise que a reconstrução deve incorporar. Essas por sua vez, foram cruzadas com as áreas operacionais relevantes ao contexto arqueológico e o resultado foi a limitação da avaliação à digitalização, comparação e materialização das áreas abordadas. Na digitalização há a criação de uma contraparte virtual do artefato juntamente com suas informações de captação e reconstrução. A subsequente comparação busca usar, por meio da descrição da peça, sua relação com o artefato real. E a materialização envolve a plataforma de apresentação do mesmo. Considerando esses elementos e relacionando-os com os requisitos levantados no local o resultado deve compreender a precisão como captura da forma, tamanho e detalhes finos, a habilidade de operação e o custo.

A partir daí foram selecionados quatro objetos apresentando morfologias distintas, mas que representassem grupos maiores de objetos das coleções existentes da Transnordestina. Esses objetos foram então submetidos a sessões de captura usando diferentes métodos e montagens de câmera com o fim de adequar o melhor processo visando habilidades facilmente adquiridas. Então dois métodos foram escolhidos, um utilizando fluxo de vídeo de profundidade e fotogrametria por vídeo em alta resolução. O primeiro utiliza de um método de triangulação de luz estruturada para a geração de quadros de profundidade, enquanto que o segundo utiliza do método de Structure from Motion com câmera não calibrada.

Os artefatos digitais foram então comparados com um substituto equivalente capturado por meio de um scanner à laser utilizando time-of-flight e com precisão de até $10 \mu \mathrm{m}$. Uma vez devidamente registrados (alinhados), os resultados foram divididos. Enquanto que na captação com a câmera de vídeo artefatos com maior quantidade de detalhes e forma bem definidas se mostraram mais precisos, os mesmos objetos tiveram maior índice de erro quando captados pela câmera de profundidade. Contudo, a média de erro fornecida pela SR300 foi substancialmente maior com apenas uma exceção, a machadinha (ref1639), onde conseguiu ser bem mais precisa atingindo um patamar de aproximadamente $9 \%$ de erro. A fotogrametria por vídeo também forneceu um resultado um pouco fora do padrão para o vaso 
(ref3733), o que indica que cada método favorece determinados aspectos do artefato em captação podendo se concluir então que a SR300 favorece elementos com superfícies suaves e pontos de referências bem aparentes, enquanto que o outro método favorece elementos com grandes áreas, pontos de referência e detalhes finos.

Ambos os métodos fornecem alto índice de rastreabilidade, visto que, as habilidades necessárias para realizar a reconstrução se estendem à manter um controle de distância entre o alvo e a câmera, movimentação lenta, captação de 360ํำ em duas alturas diferentes, transferência desses dados para análise, seleção dos quadros do vídeo, aplicação do algoritmo aos quadros para geração de um point cloud denso e, por fim, a aplicação do algoritmo para a criação de superfície. Esse caminho favorece grande flexibilidade já que pode ser executado por iniciantes com bons resultados e resultados melhores variando com a habilidade e o equipamento utilizado. E também pela possibilidade de incorporar dados específicos aos processos que levaram à construção do objeto estendendo a rastreabilidade do mesmo.

Os resultados podem ser materializados através de ambientes virtuais utilizando como formato padrão o OBJ para manter as informações de malha, textura e escala. Além de utilizados em vários meios para obter maior performance no julgamento espacial do artefato, como o uso de realidade virtual para que a imersão proveja comparações que favoreçam maior precisão por percepção [LAHA, BOWMAN e SOCHA, 2014].

Os resultados práticos desse trabalho colaboram para a comprovação da possível facilitação e aplicabilidade da captação e arquivamento de dados digitais de artefatos arqueológicos musealizados. Dessa maneira, mostra que é possível a aproximação e instrumentalização de tais tecnologias da vida prática de profissionais da área, tanto em cursos de formação quanto em campo, permitindo estudos mais robustos em ambientes ricos em dados e agregando ao contexto de herança virtual. 


\subsection{TRABALHOS FUTUROS}

A aplicação de objetos reconstruídos requer que o artefato digital percorra um caminho parecido com o que percorreu o artefato real no ambiente museal, vemos que as peças obtidas ficam um tanto quanto deslocadas quanto ao seu uso, pois a qualidade da reconstrução interfere diretamente disso. Da mesma forma que o artefato real é semióforo, o digital também o é o sentido de conter informação transformadora e mutante sobre o que é o objeto. A capacidade de incorporação de metadados a peças de cunho patrimonial somado ao método de materialização pode agir como alavanca de transformação na relação que temos com nossa história.

Para que isso aconteça então, está em ordem um mapeamento dos objetivos dentro da documentação e da educação patrimonial, para fim de encontrar as aplicações específicas para cada nível de qualidade captado, bem como também quais os diferentes níveis de metadados devem estar incorporados para que o artefato digital tenha poder transformador. Assim, esses metadados devem ser devidamente relacionados aos resultados obtidos após novas experimentações, além de extensas entrevistas em núcleos de especialistas com objetivos diferentes para validação por peça [LIMP et al, 2011], [KULASEKARAN et al, 2014]. Levando assim a uma avaliação qualitativa com a incorporação de níveis de textura usando como base os resultados obtidos. 


\section{REFERÊNCIAS}

Aiger D., Mitra N. J., e Cohen-Or D. (2008). "4-points congruent sets for robust pairwise surface registration". Em ACM Trans. Graph. 27, 3, Artigo 85 (Agosto 2008), 10 páginas. DOI: https://doi.org/10.1145/1360612.1360684

Alonso, J. I. S. J., Rubio, J. M., Martín, J.J. F., Fernández, J. G. (2011). "Comparing Time-Of-Flight And Phase-Shift. The Survey Of The Royal Pantheon In The Basilica Of San Isidoro (León)". International Archives of the Photogrammetry, Remote Sensing and Spatial Information Sciences, Volume XXXVIII-5/W16, 2011. ISPRS Trento 2011 Workshop, 2-4 March 2011, Trento, Italy

AMNH - American Museum of Natural History. (2013). "Using 3D Printing to Reconstruct Dinosaurs, Students Learn to Think Like Paleontologists". http://www.amnh.org/explore/news-blogs/education-posts/students-use-3dprinting-to-reconstruct-dinosaurs/. Acessado em: <Outubro de 2015>.

Andreadis, A., Gregor, R., Sipiran, I., Mavridis, P., Papaioannou, G., \& Schreck, T. (2014). "Fractured 3D Object Restoration and Completion". Em Proc. EUROGRAPHICS Workshop on Graphics and Cultural Heritage. 74.

Antunes, B. C., Costa, S. A., Ruivo, M. L. (2013). "Dificuldades de Inserir a Temática Paleontologia na Sala de Aula Em Belém - Pa”. Em Anais do 13ํㅗㄴósio de Geologia da Amazônia. v. 1. p. 22-25.

Azevedo, T. C., Tavares, J. M. R., \& Vaz, M. A. (2009). "3D object reconstruction from uncalibrated images using an off-the-shelf camera. In Advances in computational vision and medical image processing". (pp. 117-136). Springer Netherlands.

BesI, P. J., \& McKay, N. D. (1992). "Method for registration of 3-D shapes. In Sensor Fusion IV: Control Paradigms and Data Structures". (Vol. 1611, pp. 586-607). International Society for Optics and Photonics.

Biasotti, S., Cerri, A., Falcidieno, B., \& Spagnuolo, M. (2015). "3D artifacts similarity based on the concurrent evaluation of heterogeneous properties". Journal on Computing and Cultural Heritage (JOCCH), 8(4), 19.

Bruno, M.C.O. Museologia e Museus: os inevitáveis caminhos entrelaçados. Cadernos de Sociomuseologia no 25. Lisboa, Universidade Lusófona de Humanidades e Tecnologias - CeiED. 2006: $5-20$.

Musealização da Arqueologia: caminhos percorridos. Revista de Arqueologia, vol. 26, no 2; vol. 27, ํㅜ 1. SAB. 2013 - 2014: 4- 15 .

Buna, Z., Popescu, D., Comes, R., Badiu, I., \& Mateescu, R. (2014). "ENGINEERING CAD TOOLS IN DIGITAL ARCHAEOLOGY". In Mediterranean Archaeology and Archaeometry, 14(4), 83-91.

Cantoni V., Levialdi S. e Roberto V.. (1997). "4 - Active Model Acquisition and Sensor Planning, In Signal Processing and its Applications". Academic Press, San Diego, 1997, p 65-85, Artificial Vision: Image Description, Recognition, and Communication, ISBN 9780124448162, https://doi.org/10.1016/B978-0124448162/50008-3.

Carlan, Claudio U. (2008). Os museus e o patrimônio histórico: uma relação complexa. História (São Paulo), 27(2), 75-88. https://dx.doi.org/10.1590/S010190742008000200005 
Cassab, R. C. T. (2004). "Objetivos e Princípios". In CARVALHO, I.S. (ed.) Paleontologia. $2^{\underline{a}}$ ed. Interciência, Rio de Janeiro, Brasil, v.1, p. 3-11.

Cherin, M., lurino, D. A., Sardella, R., \& Rook, L. (2014). "Acinonyx pardinensis (Carnivora, Felidae) from the Early Pleistocene of Pantalla (Italy): predatory behavior and ecological role of the giant Plio-Pleistocene cheetah". In Quaternary Science Reviews, 87, 82-97.

Ch'ng, E. (2007). “Using Games Engines for Archaeological Visualisation: Recreating Lost Worlds". In CGgames '07. Wolverhampton, Reino unido.

Cignoni P., Callieri M., Corsini M., Dellepiane M., Ganovelli F., Ranzuglia G. (2008). MeshLab: an Open-Source Mesh Processing Tool. Sixth Eurographics Italian Chapter Conference, p 129-136.

Cunningham, J. A., Rahman, I. A., Lautenschlager, S., Rayfield, E. J., \& Donoghue, P. C. (2014). "A virtual world of paleontology". In Trends in ecology \& evolution, 29(6), 347-357.

Debevec, Paul. (2012) "The Light Stages and Their Applications to Photoreal Digital Actors". SIGGRAPH Asia. Technical Briefs.

Demetrescu, E. (2015). "Archaeological stratigraphy as a formal language for virtual reconstruction". In Theory and practice. Journal of Archaeological Science, 57, 4255.

Doyle, F. (1964). "The Historical Development of Analytical Photogrammetry". Photogrammetric Engineering and Remote Sensing. 46 (7). p. 923-936.

EDF. (2018). CloudCompare 2.9.1. Software de mídia digital.

Funari, P. P. A. (2007). Teoria e a arqueologia histórica: a América Latina e o mundo. Vestígios: revista Latino-Americana de Arqueologia Histórica, 1(1), 49-58.

Fürst, J., Fierro, G., Bonnet, P., \& Culler, D. E. (2014, Novembro). "BUSICO 3D: building simulation and control in unity 3D". In Proceedings of the 12th ACM Conference on Embedded Network Sensor Systems (pp. 326-327). ACM.

Gaspard, D. (2014). "Noteworthy brachiopods of the Cenomanian stratotype: A synthesis of the biochronological, palaeoenvironmental and palaeoecological implications". In Geobios, 47(6), 347-370.

Goerlach, F. S., Lueddemann, T., Pfeiffer, J., \& Lueth, T. C. (2014, Agosto). "Detection of surface points with an 850nm laser and an NDI stereo camera". In Biomedical Robotics and Biomechatronics. In (2014 5th IEEE RAS \& EMBS International Conference on (pp. 719-725). IEEE.

Gonçalves, A., Rodrigues, N., \& Hipólito-Correia, V. (2017, Junho). "Conimbriga as paradigm of cultural heritage (virtual) recreation". In Information Systems and Technologies (CISTI), 2017 12th Iberian Conference on (pp. 1-6). IEEE.

Hess, M., Serpico, M., Amati, G., Pridden, I., Nelson, T., \& Robson, S. (2014). "Developing 3D imaging programmes-workflow and quality control". Journal on Computing and Cultural Heritage (JOCCH), 9, 1.

Hsieh, J. (2009, Novembro). Computed tomography: principles, design, artifacts, and recent advances. Bellingham, WA: SPIE. 
Hughes, Stephen. (2011). CT scanning in archaeology. INTECH Open Access Publisher.

INTEL. (2016). Intel ${ }^{\circledR}$ RealSense ${ }^{\mathrm{TM}}$ Camera SR300, Embedded Coded Light 3D Imaging System wit Full High Definition Color Camera. https://www.mouser.com/pdfdocs/intel_realsense_camera_sr300.pdf. Acessado em: <Novembro de 2016>

Johnson, L., Adams Becker, S., Estrada, V., and Freeman, A. (2015). "NMC Horizon Report: Edição Educação Básica 2015". Austin, Texas: The New Media Consortium.

Kazhdan, M., Hoppe H. (2013). Screened poisson surface reconstruction. ACM Transactions on Graphics (TOG), 32(3), 29.

Ketcham, R. A., \& Carlson, W. D. (2001). Acquisition, optimization and interpretation of X-ray computed tomographic imagery: applications to the geosciences. Computers \& Geosciences, 27(4), 381-400.

Knibbe, J., O'Hara, K. P., Chrysanthi, A., Marshall, M. T., Bennett, P. D., Earl, G., ... \& Fraser, M. (2014, Fevereiro). "Quick and dirty: streamlined 3D scanning in archaeology". In Proceedings of the 17th ACM conference on Computer supported cooperative work \& social computing (pp. 1366-1376). ACM.

Kulasekaran, S., Trelogan, J., Esteva, M., \& Johnson, M. (2014, Outubro). Metadata integration for an archaeology collection architecture. In Proceedings of the International Conference on Dublin Core and Metadata Applications. DC-2014-The Austin Proceedings (pp. 53-63).

Laha, B., Bowman, D., \& Socha, J. J. (2014). "Effects of VR system fidelity on analyzing isosurface visualization of volume datasets". In Visualization and Computer Graphics, IEEE Transactions on, 20(4), 513-522.

Lapp, E., \& Nicoli, J. (2014). "Exploring 3D modeling, fingerprint extraction, and other scanning applications for ancient clay oil lamps". In Digital Applications in Archaeology and Cultural Heritage, 1(2), 34-44.

Laycock, S. D., Bell, G. D., Corps, N., Mortimore, D. B., Cox, G., May, S., \& Finkel, I. (2015). "Using a Combination of Micro--Computed Tomography, CAD and 3D Printing Techniques to Reconstruct Incomplete 19th-Century Cantonese Chess Pieces". Journal on Computing and Cultural Heritage (JOCCH), 7(4), 25.

Leonov, A. V., Anikushkin, M. N., Bobkov, A. E., Rys, I. V., Kozlikin, M. B., Shunkov, M. V., ... \& Baturin, Y. M. (2014). "Development of a Virtual 3d Model of Denisova Cave in the Altai Mountains". In Archaeology, Ethnology and Anthropology of Eurasia, 42(3), 14-20.

Li, E., Zhang, X., \& Chen, Y. (2014, Novembro). "Symmetry Based Chinese Ancient Architecture Reconstruction from Incomplete Point Cloud". In Digital Home (ICDH). In 2014 5th International Conference on (pp. 157-161). IEEE.

Limp, F., Payne, A., Simon, K., Winters, S., \& Cothren, J. (2011). Developing a 3-D digital heritage ecosystem: From object to representation and the role of a virtual museum in the 21st century. Internet Archaeology, 30.

Mallison, H., Hohloch, A., \& Pfretzschner, H. U. (2009). Mechanical digitizing for paleontology-new and improved techniques. Palaeontologia Electronica, Volume 12, Número 2, 1-41. 
Maglo, A., Lavoué, G., Dupont, F., \& Hudelot, C. (2015). "3D Mesh Compression: Survey, Comparisons, and Emerging Trends". ACM Computing Surveys (CSUR), 47(3), 44.

Miles, H. C., Wilson, A. T., Labrosse, F., Tiddeman, B., Griffiths, S., Edwards, B., ... \& Roberts, J. C. (2015). "Alternative Representations of 3D-Reconstructed Heritage Data". Journal on Computing and Cultural Heritage (JOCCH), 9(1), 4.

Mitsopoulou, V., Michailidis, D., Theodorou, E., Isidorou, S., Roussiakis, S., Vasilopoulos, T., ... \& Theodorou, G. (2015). "Digitizing, modelling and 3D printing of skeletal digital models of Palaeoloxodon tiliensis (Tilos, Dodecanese, Greece)". In Quaternary International, 379, 4-13.

Moraes, S. S., Santos, J. F., Brito, M. (2007). "Importância dada à paleontologia na educação brasileira: Uma análise dos PCN e dos livros didáticos utilizados nos colégios públicos de Salvador - Bahia". In Paleontologia: Cenários da Vida, Volume 2. Editora Interciência, Rio de Janeiro, Brasil.

Neamţu, C., Popescu, D., Mateescu, R., Suciu, L., \& Hurgoiu, D. (2014). "About Quality And Properties Of Digital Artifacts". In Mediterranean Archaeology and Archaeometry, 14(4), 55-64.

NextEngine. (2018) NextEngine 3D Scanner Ultra HD TechSpecs. Acessado em: $<$ fevereiro de 2018>.

Neves, J. P., Campos, L. L., \& Simões, M. G. (2010). “Jogos como recurso didático para o ensino de conceitos paleontológicos básicos aos estudantes do ensino fundamental". In Doi: http://dx. doi. org/10.5212/TerraPlural.v. 2i1.103114. Terr@ Plural, 2(1), 103-114.

Pavlidis G., Koutsoudis A., Arnaoutoglou F., Tsioukas V., Chamzas C. (2007, Março). "Methods for 3D digitization of Cultural Heritage". Journal of Cultural Heritage, Volume 8, Edição 1, Janeiro-Março, P.93-98, ISSN 1296-2074, http://dx.doi.org/10.1016/j.culher.2006.10.007.

Peterson, Joseph E. (2015, Setembro) "Techniques for Virtual Palaeontology por Mark D. Sutton, Imran A. Rahman, and Russell J. Garwood," The Quarterly Review of Biology 90, no. 3: - DOI: 10.1086/682601

Pintus, R., \& Gobbetti, E. (2015). "A fast and robust framework for semiautomatic and automatic registration of photographs to 3D geometry". Journal on Computing and Cultural Heritage (JOCCH), 7(4), 23.

Rahman, Imran A. e Smith, Selena Y. (2014). "Virtual paleontology: computer-aided analysis of fossil form and function". Journal of Paleontology 88(4):633-635. doi: http://dx.doi.org/10.1666/13-001I

Roosevelt, C. H., Cobb, P., Moss, E., Olson, B. R., Ünlüsoy, S. (2015). "Excavation is Destruction Digitization: Advances in Archaeological Practice". Journal of Field Archaeology. Vol. 40, Iss. 3.

Rykaczewski, Konrad. (2015, Fevereiro). "Destructive Tomography of Red Cabbage".

http://demonstrations.wolfram.com/DestructiveTomographyOfRedCabbage/.

Wolfram Demonstrations Project. Acessado em: <maio de 2016> 
Saladino, A. Iphan, arqueólogos e patrimônio arqueológico brasileiro: um breve panorama. Revista de Arqueologia, vol. 26, $n \div 2$; vol. 27, nํ 1. SAB. $2013-2014$ : $41-58$.

Santos, M.C.T.M. Processo museológico e educação: Construindo um museu didático-comunitário. Edições Universitárias Lusófonas, Bahia, 1996. Endereço: $<$ http://biblioteca.versila.com/2302764/processo-museologico-e-educacaoconstruindo-um-museu-didatico-comunitario $>$. Acessado em: $<15$ de junho de 2016>

Sismanoglu, B. N., Germano, J. S. E., Amorim, J. e Caetano, R. (2009). "A utilização da filmadora digital para o estudo do movimento dos corpos". Revista Brasileira de Ensino de Física, v. 31, n. 1, 1501, São José dos Campos, SP.

Schwarz, D., Vontobel, P., Lehmann, E. H., et al. (2005). Neutron tomography in internal structures of vertebrate remains: A comparison with $X$-Ray computed tomography. Palaeontologia Electronica, 8 (2), 30A.

Shott, M. (2014). Digitizing archaeology: A subtle revolution in analysis. World Archaeology, 46(1), 1-9. doi:10.1080/00438243.2013.879046

Sutton, Mark D., Rahman, Imran A. e Garwood, Russell J. (2014). Techniques for Virtual Palaeontology. New Analytical Methods in Earth and Environmental Science. Editora Wiley Blackwell. Hoboken (New Jersey). ISBN: 978-1-118-59113-0. Livro Eletrônico.

Tate, J. R. Cann, C. E. (1982). High-Resolution computed tomography for the comparative study of fossil and extant bone. American Journal of Physical Anthropology, p. 58 (1), 67 - 73. Versão online: 27 de Abril de 2005. DOI: 10.1002/ajpa.1330580108.

Torres, R., Yamafune, K., Castro, F., Ferreira, S. (2017). "Mapeando em Profundidade: A integração de Técnicas Digitais Para a Pesquisa Arqueológica de Sítios de Naufrágios Históricos". Revista Latino-americana de Arqueologia Histórica - VESTÍGIOS. Volume 11. № 1. Janeiro - Junho 2017.

VirtualDub. (2013). v1.10.4 (stable). Software de mídia digital.

Weber, G. W. (2014). "Another link between archaeology and anthropology: Virtual anthropology", Digital Applications in Archaeology and Cultural Heritage, Volume 1, Edição 1, P.3-11, ISSN 2212-0548, http://dx.doi.org/10.1016/j.daach.2013.04.001.

Wichers, C.A.M. Parte 1: A Produção acadêmica em musealização da arqueologia no Brasil - Dois enquadramentos, um mesmo problema: Os desafios da relação entre museus, sociedade e patrimônio arqueológico. Revista de Arqueologia, vol. 26, no 2; vol. 27, no 1. SAB. 2013 - 2014: 4 - 15.

Zhang, K., Yu, W., Manhein, M., Waggenspack, W., \& Li, X. (2015, Agosto). "Reassembling 3D thin shells using integrated template guidance and fracture region matching". In ACM SIGGRAPH 2015 Posters (p. 88). ACM. 


\begin{abstract}
ANEXOS
Peças de referências encontradas nos estados do Ceará e Pernambuco, no trecho Missão Velha - Salgueiro, sob o Programa de resgate do Patrimônio Arqueológico, Histórico e Cultural da Ferrovia Transnordestina.
\end{abstract}

- Ponta de Flecha (Ref.: Col Sup 001)

- Sítio: Doação - Povoado do Cardoso

- Proveniência: Col. Sup. Pto 001

- Nível: Sup

○ Data: $13 / 10 / 08$

- Lote: $1, \mathrm{~N}^{\circ}$ Individual: 01

- Obs.: 24M494993 9155402

- Machadinha (Ref.: 1639)

- Sítio: Baixio do Caboclos

o Proveniência: Col. Sup. Sw 13.218

- Nível: Sup

- Lote: $480, N^{\circ}$ Individual: 1639

- Vaso (Ref.: 3733)

- Sítio: Baixio do Lopes

- Proveniência: UE1Q4

- Nível: 10-20 20-30

- Lote: 351 e 352, No Individual: 3731 a 3747

- Borda de Vaso (Ref.: 1007-1008/1014)

- Sítio: Baixio do Lopes

- Lote: 339 , № Individual: 1007-1008/1014 